\title{
Effect of isoform-specific HIF-1a and HIF-2a antisense oligonucleotides on tumorigenesis, inflammation and fibrosis in a hepatocellular carcinoma mouse model
}

\author{
Bart Vanderborght ${ }^{1,2}$, Kevin De Muynck ${ }^{1,2}$, Sander Lefere ${ }^{1,2}$, Anja Geerts ${ }^{1}$, Helena \\ Degroote $^{1,2}$, Xavier Verhelst ${ }^{1}$, Hans Van Vlierberghe ${ }^{1}$ and Lindsey Devisscher ${ }^{2}$ \\ ${ }^{1}$ Department of Internal Medicine and Pediatrics, Department of Gastroenterology and Hepatology, Hepatology Research \\ Unit, Ghent University, Ghent, Belgium \\ ${ }^{2}$ Department of Basic and Applied Medical Sciences, Gut-Liver Immunopharmacology Unit, Ghent University, Ghent, Belgium \\ Correspondence to: Lindsey Devisscher, email: lindsey.devisscher@ugent.be
}

Keywords: hepatocellular carcinoma; hypoxia-inducible factor; antisense oligonucleotides; tumor microenvironment; experimental mouse model

Received: July 09, $2020 \quad$ Accepted: November 19, $2020 \quad$ Published: December 01, 2020

Copyright: () 2020 Vanderborght et al. This is an open access article distributed under the terms of the Creative Commons Attribution License (CC BY 3.0), which permits unrestricted use, distribution, and reproduction in any medium, provided the original author and source are credited.

\section{ABSTRACT}

Hepatocellular carcinoma (HCC) is one of the leading causes of cancer-related death worldwide. For advanced HCC, there is still an unmet need for more effective therapeutic strategies. HCC is typically associated with hypoxia and the hypoxiainducible factor (HIF) regulatory pathway plays an important role in HCC development and progression. Therefore, we investigated the therapeutic potential of isoformspecific HIF-1a and HIF-2a antisense oligonucleotides (ASOs), along with their effect on the inflammatory and fibrotic component of the tumor microenvironment (TME), in an experimental HCC mouse model. Based on its efficacy and safety, a dosage regimen of $20 \mathrm{mg} / \mathrm{kg}$ intraperitoneal injection of HIFa ASO twice per week was selected for further investigation in a preventive and therapeutic setting in a $\mathrm{N}, \mathrm{N}-$ diethylnitrous amide (DEN)-induced HCC mouse model. DEN administration resulted in $100 \%$ tumor formation and HIFa ASO administration led to effective and selective hepatic downregulation of its target genes. HIFa ASO treatment had no effect on tumor numbers, but even enhanced the increased hepatic expression of HCC tumor markers, a-fetoprotein and glypican-3, compared to scrambled control ASO treatment in HCC mice. Especially HIF-1a ASO treatment resulted in an enhanced increase of monocytes and monocyte-derived macrophages in the liver and an enhanced hepatic upregulation of inflammatory markers. Both HIFa ASOs aggravated liver fibrosis in HCC mice compared to scrambled ASO treatment. The observed effects of our dosing regimen for HIF-1a and HIF-2a ASO treatment in the DEN-induced HCC mouse model discourage the use of HIFa isoforms as targets for the treatment of HCC.

\section{INTRODUCTION}

Hepatocellular carcinoma (HCC) represents the majority of primary liver cancer cases and is currently the fourth most common cause of cancer-related death worldwide [1-2]. HCC usually occurs in a background of chronic liver disease, mainly caused by viral hepatitis, chronic alcohol abuse or non-alcoholic fatty liver disease (NAFLD) $[1,3]$. This environment of repetitive hepatic damage and genomic instability contributes to the broad array of genetic and epigenetic alterations by which the heterogeneous molecular pathogenesis of this malignancy is characterized [4]. A frustrating discrepancy exists between the stage at which HCC is commonly first diagnosed and the stage at which curative treatment options are currently available [3]. HCC is an aggressive cancer and is often diagnosed at an advanced stage, while possible curative interventions, including ablation, resection and liver transplantation, are only effective at an early disease stage $[3,5]$. For advanced HCC, several 
systemic therapies with minor survival benefits and considerable adverse events are available in the form of multikinase inhibitors and immune checkpoint inhibitors. Currently, two oral tyrosine kinase inhibitors are approved as first-line treatment of advanced HCC, namely sorafenib and lenvatinib $[1,2]$. For second-line treatment, the currently approved options are the multitargeted tyrosine kinase inhibitors regorafenib and cabozantinib, and the human monoclonal vascular endothelial growth factor receptor (VEGFR)2-targeting antibody ramucirumab, which all yield only limited clinical benefits [2]. In addition to these targeted therapies, immune-based therapies are, due to their relatively higher response rates, emerging as promising treatment options for advanced HCC. Currently, the anti-programmed cell death protein 1 (PD-1) antibodies nivolumab and pembrolizumab are the only immune checkpoint inhibitors approved as second-line therapy for advanced HCC following failure of sorafenib $[1,6]$. The clinical benefit of other immune checkpoint-targeting therapies, including the cytotoxic T-lymphocyte-associated protein 4 (CTLA-4) inhibitor tremelimumab, and the synergistic effect of combination therapies of kinase inhibitors, immune checkpoint inhibitors and/or locoregional therapies are being extensively investigated in clinical trials [6]. However, despite the emergence of immunotherapy in the treatment landscape of HCC, there is still an unmet need for more effective therapeutic strategies [7].

In order to sustain their tumorigenicity and proliferative behavior, HCC cells have the ability to metabolically adapt to a nutrient-deprived microenvironment [8-9]. Indeed, cancer cells are able to reprogram their energy metabolism towards aerobic glycolysis, a phenomenon called the Warburg effect [10-12]. Due to the oxygen-consuming hypermetabolism of the rapidly proliferating tumor cells, HCC is typically associated with hypoxia in the intratumoral regions [1314]. This hypoxic microenvironment promotes tumor aggressiveness and therapeutic resistance primarily through activation of the hypoxia-inducible factor (HIF) regulatory pathway $[14,15]$. This hypoxia-responsive pathway consists of $\alpha$-subunits (HIF $\alpha$, including HIF- $1 \alpha$, HIF- $2 \alpha$ / EPAS1 and HIF-3 $\alpha$ ) and $\beta$-subunits (HIF $\beta$, including HIF1ß/ARNT1, ARNT2 and ARNT3) [15]. Under normoxia, the HIF $\alpha$ subunit is hydroxylated at two proline residues by prolyl hydroxylase domain-containing protein (PHD), and subsequently ubiquitinated by von Hippel-Lindau tumor suppressor protein (pVHL) and degraded by the $26 \mathrm{~S}$ proteasome. Additionally, factor inhibiting HIF (FIH) mediates asparaginyl hydroxylation of $\mathrm{HIF} \alpha$, thereby inhibiting its interaction with transcriptional coactivators CREB-binding protein (CBP) and p300. Both PHD and FIH are oxygen-dependent enzymes, which implies that they are inactive under hypoxic conditions. Therefore, in hypoxia-associated cancers, including HCC, the HIF $\alpha$ subunit is stabilized, leading to its nuclear translocation.
After dimerization with the constitutively expressed HIF $\beta$ subunit, and interaction with transcriptional activators CBP and p300, the resultant heterodimer acts as a transcription factor, upregulating the expression of a large number of hypoxia-responsive target genes by binding to the hypoxia response element (HRE) in their promoter region $[13,15]$. These genetic targets comprise multiple cancer hallmark-implicated genes, including genes involved in 1) angiogenesis, such as vascular endothelial growth factor (VEGF), erythropoietin (EPO) and platelet-derived growth factor (PDGF); 2) metabolism, such as glucose transporter 1 (GLUT1), glyceraldehyde 3-phosphate dehydrogenase (GAPDH) and phosphoglycerate kinase 1 (PGK1); 3) proliferation, such as insulin-like growth factor 2 (IGF-2) and transforming growth factor (TGF)- $\alpha$; and 4 ) invasion and metastasis, such as lysyl oxidase (LOX) and several matrix metalloproteinases (MMPs). Thus, in HCC and other hypoxia-associated tumors, the HIF pathway has a key role in shaping the tumor microenvironment (TME) $[13,15-18]$. Consequently, targeting hypoxia and, more specifically, the HIF pathway appears to be a plausible therapeutic strategy for the treatment of HCC [13, 15]. To date, in addition to downstream HIF signaling pathwaytargeting strategies, including the approved VEGFRtargeting drugs sorafenib, lenvatinib, regorafenib, cabozantinib and ramucirumab, an array of HIF-targeting compounds have been identified and investigated in preclinical studies and clinical trials [13, 15, 19-20]. A substantial part of these HIF-targeting compounds are inhibitors of HIF messenger ribonucleic acid (mRNA) or protein expression. These include compounds that 1) target the phosphoinositide 3-kinase/protein kinase B/ mammalian target of rapamycin (PI3K/AKT/mTOR) pathway (regulates $\mathrm{HIF} \alpha$ mRNA translation), 2) inhibit topoisomerase 1 (regulates HIF $\alpha$ mRNA translation), 3) directly target HIF- $1 \alpha$ mRNA expression (synthetic HIF$1 \alpha$ antisense oligonucleotides), 4) disrupt microtubules (orchestrate HIF $\alpha$ mRNA translation), 5) inhibit heat shock protein 90 (Hsp90), which induces proteasomal degradation of $H I F \alpha, 6)$ inhibit histone deacetylase (HDAC), which inhibits nuclear translocation of HIF $\alpha$, or 7) promote iron-regulatory protein 1 /iron-responsive element (IRP1/IRE) interaction (HIF-2 $\alpha$ translational inhibitors). Other HIF pathway-targeting compounds may act through inhibition of HIF $\alpha / \mathrm{HIF} \beta$ dimerization, by inhibiting binding of HIF to the HRE of its target genes, or by inhibiting transcriptional activity of HIF (e.g., by inhibiting interaction of HIF with transcriptional coactivator p300) $[13,15,19]$. Despite this already significant amount of HIF pathway-targeting options, only a few of them have moved beyond the preclinical stage for therapeutic application in HCC $[13,15]$. One of the most important limitations of these compounds is their lack of specificity towards a certain isoform of HIF, as the different isoforms, in addition to a substantial overlap, also have substantial differences in their array of target 
genes, and this may lead to opposing effects on the TME. Therefore, due to the relevance of the HIF pathway in several aspects of HCC development and progression, it is of great importance to further explore the therapeutic potential of isoform-specific HIF pathway-targeting strategies and their effect on the TME $[13,15,19]$. Here, we investigated the therapeutic potential of isoformspecific HIF-1 $\alpha$ and HIF-2 $\alpha$ antisense oligonucleotides (ASOs; provided by Ionis Pharmaceuticals), along with their effect on several TME-associated features, including inflammation and fibrosis, in a N,N-diethylnitrous amide (DEN)-induced HCC mouse model.

\section{RESULTS}

\section{Pilot study for selection of optimal dosage regimen}

In order to define the optimal dosage regimen of the isoform-specific HIF-1 $\alpha$ and HIF-2 $\alpha$ ASOs used in further experiments, healthy mice were intraperitoneally injected with 10, 20 or $100 \mathrm{mg} / \mathrm{kg} \mathrm{HIF-1} \alpha$ or HIF-2 $\alpha$ ASO, or $20 \mathrm{mg} / \mathrm{kg}$ scrambled ASO, twice per week for 2 weeks. Neither of the dosage regimens influenced the body weight of the mice. However, compared to scrambled ASO treatment, statistically significant hepatic enlargement was observed for both $100 \mathrm{mg} / \mathrm{kg} \mathrm{HIF}-1 \alpha$ and HIF-2 $\alpha$ ASO, while this was not observed for lower dosage regimens of both isoform-specific HIF $\alpha$ ASOs (Figure 1A).

Efficacy and selectivity of the HIF $\alpha$ ASOs was evaluated by comparing hepatic mRNA expression of all three HIF $\alpha$ isoforms in response to the different dosage regimens of HIF- $1 \alpha$ and HIF- $2 \alpha$ ASO, and scrambled control treatment. Both HIF $\alpha$ ASOs led to significant downregulation of mRNA expression of their respective target gene in a dose-dependent manner, compared to scrambled ASO treatment. The expression of HIF-1 $\alpha$ was unaffected by HIF- $2 \alpha$ ASO treatment, whereas HIF- $1 \alpha$ ASO treatment showed a significant but neglectable effect (less than 2-fold change) on HIF-2 $\alpha$ expression. Neither of the isoform-specific HIF $\alpha$ ASO treatments affected mRNA expression of the HIF-3 $\alpha$ isoform (Figure 1B).

Potential liver injury of the different dosage regimens was assessed via hepatic mRNA expression of several inflammation-associated markers. Compared to scrambled ASO treatment, expression of the proinflammatory cytokine tumor necrosis factor $(\mathrm{TNF}) \alpha$, vascular cell adhesion molecule (VCAM)-1 (mediates adhesion of several immune cells to vascular endothelium), C-C motif chemokine ligand (CCL)2 (mediates monocyte
A

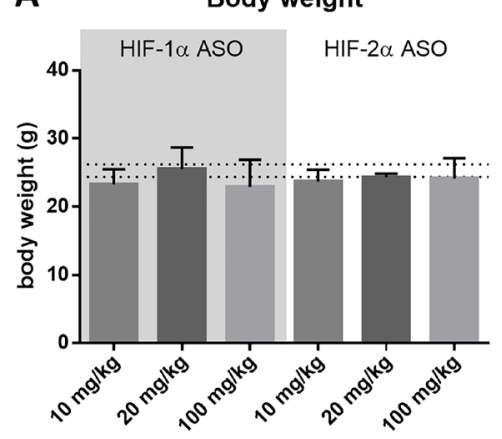

B



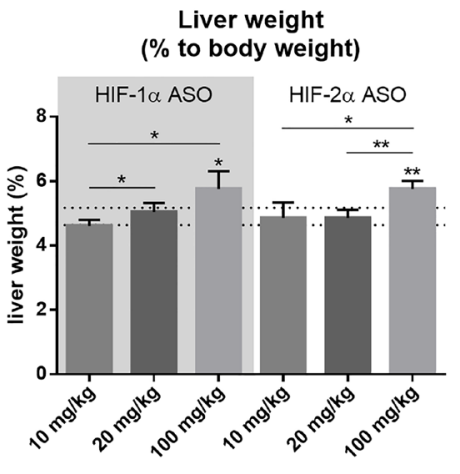

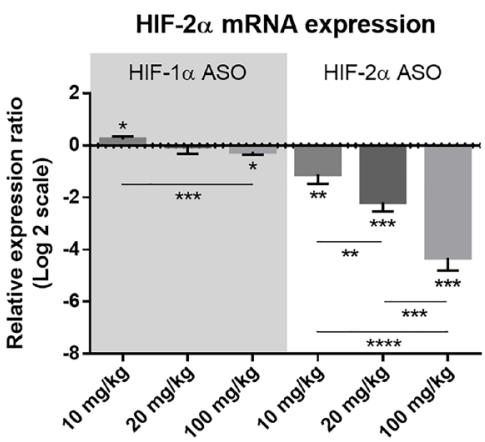

Figure 1: Efficacy and selectivity of different dosage regimens of HIF-1 $\alpha$ and HIF-2 $\alpha$ ASO. Mice were intraperitoneally injected with 10, 20 or $100 \mathrm{mg} / \mathrm{kg} \mathrm{HIF-1} \alpha$ or HIF-2 $\alpha$ ASO, or $20 \mathrm{mg} / \mathrm{kg}$ scrambled ASO, twice per week for 2 weeks. (A) Body weight and relative liver weight (expressed as $\%$ to body weight) following treatment period. The upper and lower dashed lines represent mean \pm SD of the scrambled ASO data. Mean $\pm \mathrm{SD}$ of other data are represented as bars ( $n=4$ per treatment group). (B) Hepatic mRNA expression of the HIF $\alpha$ isoforms following treatment period. The upper and lower dashed lines represent mean \pm SD of the log2-transformed $20 \mathrm{mg} / \mathrm{kg}$ scrambled ASO data. Log2-transformed mean $\pm \mathrm{SD}$ of other data, relative to the log2-transformed mean of the $20 \mathrm{mg} / \mathrm{kg} \mathrm{scrambled} \mathrm{ASO}$ treatment group, are represented as bars ( $n=4$ per treatment group). ${ }^{*} p<0.05,{ }^{* *} p<0.01,{ }^{* * *} p<0.001$ and ${ }^{* * * *} p<0.0001$. 
chemotaxis) and C-X-C motif chemokine ligand (CXCL)2 (involved in immune cell chemotaxis) was significantly upregulated following $20 \mathrm{mg} / \mathrm{kg}$ and $100 \mathrm{mg} / \mathrm{kg} \mathrm{HIF}-1 \alpha$ and HIF-2 $\alpha$ ASO treatment in a dose-dependent manner, whereas for the multifunctional cytokine TGF- $\beta$ and C-C motif chemokine receptor (CCR)2 (mediates monocyte chemotaxis), hepatic expression was only increased following $100 \mathrm{mg} / \mathrm{kg} \mathrm{HIF} \alpha \mathrm{ASO}$ treatment (Figure 2).

Based on the efficacy, as well as potential hepatotoxicity observed for the different treatment regimens, $20 \mathrm{mg} / \mathrm{kg}$ was selected as the optimal dose for further experiments.

\section{Selective and effective hepatic downregulation of target genes following HIF $\alpha$ ASO treatment in HCC mice}

Efficacy and selectivity of isoform-specific $\mathrm{HIF} \alpha$ ASO treatment was evaluated in the preventive and therapeutic setting in DEN-induced HCC mice. HIF$1 \alpha$ ASO effectively downregulated HIF-1 $\alpha$ mRNA expression in both settings compared to healthy control mice and compared to other ASO treatment groups. HIF-1 $\alpha$ expression was also slightly decreased after 15 weeks of scrambled and HIF- $2 \alpha$ ASO administration, whereas therapeutic treatment of these ASOs resulted in minor upregulation of hepatic HIF-1 $\alpha$ expression. HIF- $2 \alpha$
ASO administration also selectively downregulated the expression of its target gene compared to all other groups. In addition, therapeutic HIF-1 $\alpha$ ASO treatment resulted in minor upregulation of HIF-2 $\alpha$ expression, compared to healthy control mice. In the therapeutic setting, all HCC mice showed increased expression of HIF- $3 \alpha$ compared to healthy control mice without differences between treatment groups (Figure 3).

\section{Effect of HIF $\alpha$ ASO treatment on hepatocarcinogenesis}

The effect of isoform-specific HIF $\alpha$ ASOs on the development of HCC (preventive setting) and their potential as therapeutic strategy for HCC (therapeutic setting) were assessed in the established DEN-induced HCC mouse model, which is known to be characterized by hypoxia and induction of the HIF pathway [21-22]. Regardless of the ASO treatment, all DEN-injected mice showed lower body weight at the end of the experiment compared to healthy control mice, however without significance. Only preventive HIF-1 $\alpha$ ASO administration resulted in significant hepatic enlargement in HCC mice compared to healthy control mice and other treatment groups, whereas in the therapeutic setting, both HIF$1 \alpha$ and HIF- $2 \alpha$ ASO treatment resulted in significant hepatomegaly (Figure 4A).
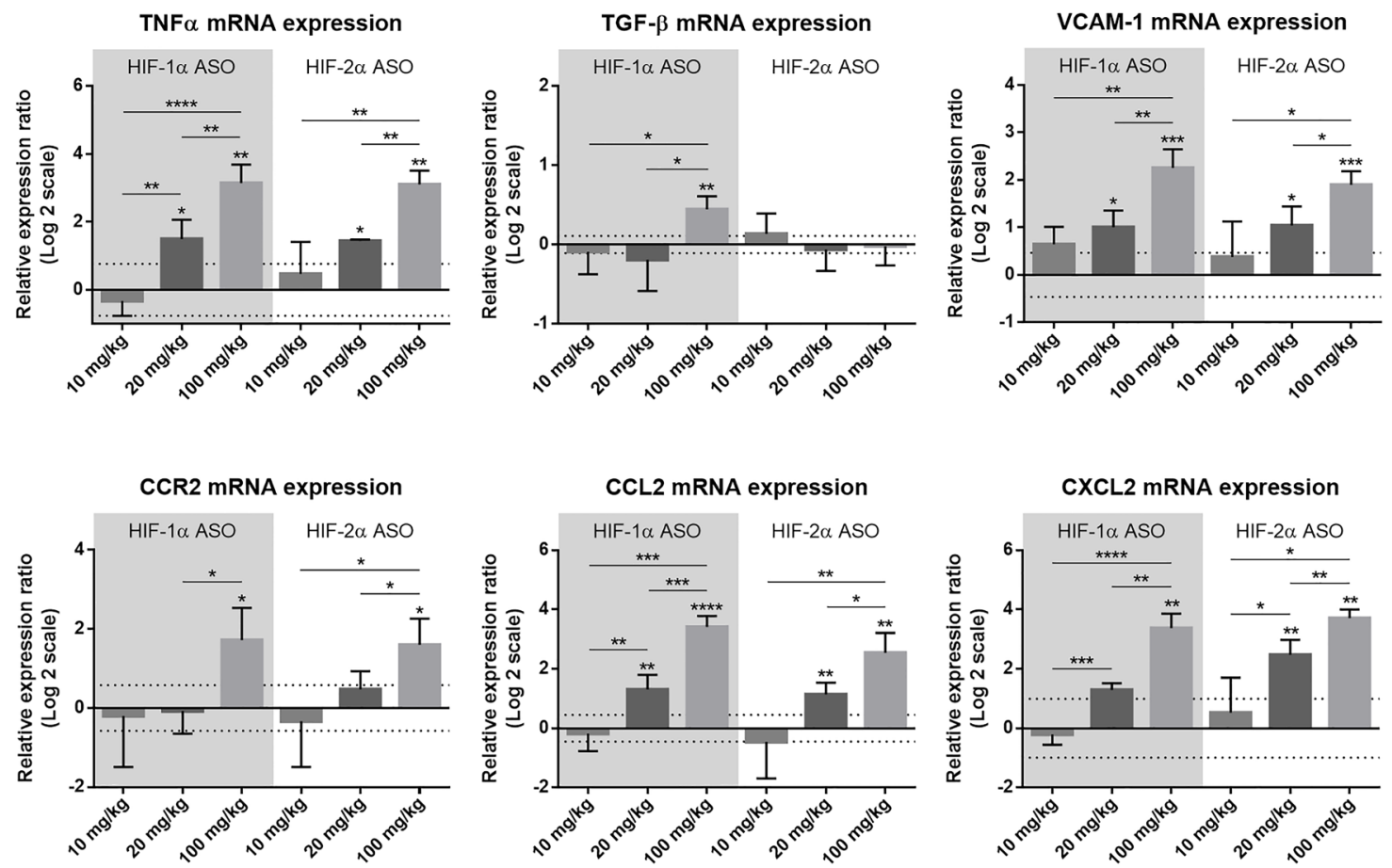

Figure 2: Effect of different dosage regimens of HIF-1 $\alpha$ and HIF-2 $\alpha$ ASO on hepatic expression of inflammatory markers. Mice were intraperitoneally injected with 10,20 or $100 \mathrm{mg} / \mathrm{kg} \mathrm{HIF-} 1 \alpha$ or HIF- $2 \alpha$ ASO, or $20 \mathrm{mg} / \mathrm{kg}$ scrambled ASO, twice per week for 2 weeks. Hepatic mRNA expression of the inflammatory markers TNF $\alpha$, TGF- $\beta$, VCAM-1, CCR2, CCL2 and CXCL2 following treatment period is shown. The upper and lower dashed lines represent mean \pm SD of the log2-transformed $20 \mathrm{mg} / \mathrm{kg} \mathrm{scrambled} \mathrm{ASO} \mathrm{data.}$ Log2-transformed mean $\pm \mathrm{SD}$ of other data, relative to the $\log 2$-transformed mean of the $20 \mathrm{mg} / \mathrm{kg}$ scrambled ASO treatment group, are represented as bars ( $n=4$ per treatment group). ${ }^{*} p<0.05,{ }^{* *} p<0.01,{ }^{* * *} p<0.001$ and ${ }^{* * * *} p<0.0001$. 
To investigate the effect of isoform-specific HIF$1 \alpha$ and HIF- $2 \alpha$ ASO on HCC tumorigenesis, the number of macroscopically visible hepatic tumoral lesions in the different treatment groups was evaluated. DEN treatment led to a rough nodular hepatic surface with multiple macroscopic lesions in all treatment groups. However, no significant effect of HIF $\alpha$ ASO treatment could be observed. The overall number of tumoral lesions was higher in HCC mice euthanized 28 weeks following first DEN injection (therapeutic setting), compared to mice that were euthanized three weeks earlier (preventive setting) (Figure 4B).

The effect of isoform-specific HIF $\alpha$ ASO treatment on $\mathrm{HCC}$ tumorigenesis was further investigated via assessment of hepatic mRNA expression of the HCC tumor markers $\alpha$-fetoprotein (AFP) and glypican-3 (GPC3). None of the HCC mice that were euthanized 25 weeks following first DEN injection showed significantly increased expression of HCC markers compared to healthy control mice, whereas all mice euthanized 3 weeks later did. With the exception of GPC3 in 15 weeks HIF-1 $\alpha$ ASO treated mice, HCC markers were upregulated in HIF $\alpha$ ASO-treated HCC mice compared to scrambled ASOtreated $\mathrm{HCC}$ mice, both in the preventive and therapeutic setting (Figure 4C).

\section{HIF-1 $\alpha$ ASO treatment induces a pro- inflammatory TME in DEN-induced HCC mice}

The effect of HIF- $1 \alpha$ and HIF-2 $\alpha$ ASO treatment on the inflammatory component of the TME in the DENinduced HCC mouse model was first assessed via flow cytometric analysis of the hepatic macrophage pool. As previously published by our group, the percentage and number of CD11b+Ly6C-F4/80+Tim4+ Kupffer cells (KCs) was significantly decreased in HCC mice, independent from treatment [23]. As expected, DEN-induced $\mathrm{HCC}$ resulted in a marked increase of CD11b+Ly6C+Ly6G- monocytes and CD11b+Ly6CF4/80+Tim4- monocyte-derived macrophages (MoMfs) in the liver, which was most pronounced in mice treated with HIF-1 $\alpha$ ASO (Figure 5).

\section{Preventive setting}
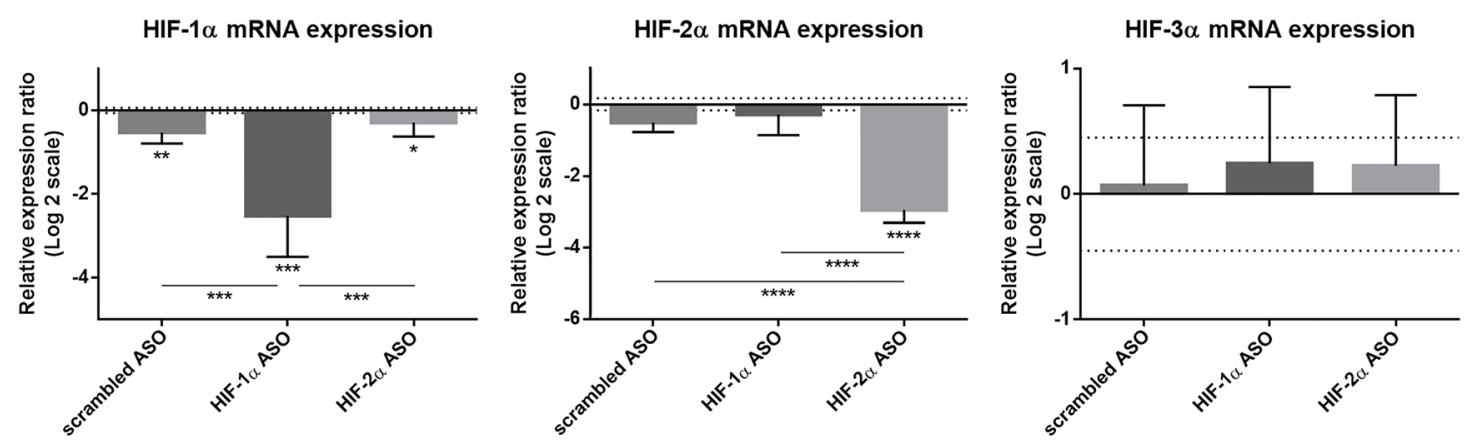

\section{Therapeutic setting}


Figure 3: Efficacy and selectivity of preventive and therapeutic HIF-1 $\alpha$ and HIF-2 $\alpha$ ASO treatment in DEN-induced HCC mice. HCC was induced by weekly intraperitoneal DEN injection for 25 weeks. Control mice received weekly intraperitoneal $0.9 \% \mathrm{NaCl}$ injection. DEN-treated mice were intraperitoneally injected with $20 \mathrm{mg} / \mathrm{kg} \mathrm{HIF}-1 \alpha \mathrm{ASO}$, HIF-2 $\alpha$ ASO or scrambled ASO twice per week, in either a preventive or a therapeutic setting. Control mice received scrambled ASO for the same duration of the experiment. Hepatic mRNA expression of the HIF $\alpha$ isoforms following preventive and therapeutic treatment is shown. The upper and lower dashed lines represent log2-transformed mean $\pm \mathrm{SD}$ of the control mice. Bars represent $\log 2$-transformed mean $\pm \mathrm{SD}$ of different treatment groups of DEN-treated mice, relative to the log2-transformed mean of the control mice ( $n=7-9$ per treatment group). ${ }^{*} p<0.05,{ }^{* *} p<0.01,{ }^{* * *} p<0.001$ and ${ }^{* * * *} p<0.0001$. 
The effect of isoform-specific HIF $\alpha$ ASO treatment on inflammation was further assessed via hepatic expression of several inflammatory markers, both at mRNA and protein level. DEN-induced HCC resulted in significant upregulation of the mRNA levels of the proinflammatory markers TNF $\alpha, \mathrm{CCR} 2, \mathrm{CCL} 2$ and VCAM1 (the latter two only in respectively the preventive and therapeutic group), and, in most settings, this was most pronounced in mice treated with HIF-1 $\alpha$ ASO. In addition, only HIF-1 $\alpha$ ASO-treated mice showed significantly increased expression of the pro-inflammatory cytokine interleukin (IL)-6 and inducible nitric oxide synthase (iNOS) (Figure 6).

While we did not observe increased protein levels of TNF $\alpha$, IL- 6 and interferon (IFN)- $\gamma$, nor effect of ASO treatment on these protein levels, in mice with $\mathrm{HCC}$, CCL2 and CCL5 protein levels, responsible for leukocyte recruitment, were significantly increased in $\mathrm{HCC}$ mice and this was most pronounced for HIF-1 $\alpha$ ASO-treated mice in the preventive setting (Figure 7).

\section{HIF $\alpha$ ASO treatment aggravates fibrosis in DEN-induced HCC mice}

In the vast majority of the cases, $\mathrm{HCC}$ develops on a fibrotic background. As hypoxia, and more specifically the HIF pathway, plays an important role in $\mathrm{HCC}$-associated fibrogenesis, we investigated the effect of isoform- specific HIF-1 $\alpha$ and HIF-2 $\alpha$ ASO treatment on fibrosis in the DEN-induced HCC mouse model $[24,25]$. DENinduced hepatocarcinogenesis only resulted in minor fibrosis, with Metavir fibrosis stages ranging from $\mathrm{F} 1$ to F2, as previously published [26]. Remarkably, HIFa ASO treatment aggravated fibrosis in the livers of DENtreated mice, both in the preventive and therapeutic setting (Figure 8).

The effect of isoform-specific HIF $\alpha$ ASO treatment on liver fibrosis was further assessed via hepatic mRNA expression of several fibrotic markers. The expression of $\alpha$-smooth muscle actin ( $\alpha$-SMA), which is a marker for the formation of extracellular matrix (ECM)-producing myofibroblasts, confirmed our histological analysis with significant upregulation in HIF $\alpha$ ASO-treated HCC mice. Furthermore, several matrix metalloproteinases (MMPs) and tissue inhibitors of metalloproteinases (TIMPs) involved in fibrogenesis and HCC progression were upregulated in the livers of HCC mice, which was again most pronounced following HIF $\alpha$ ASO treatment (Figure 9).

\section{DISCUSSION}

Due to the worldwide increase of the incidence of some of its major etiological risk factors, including chronic alcohol abuse and NAFLD, HCC is a growing health problem $[1,27-28]$. It is often only diagnosed at
A



Therapeutic setting





B
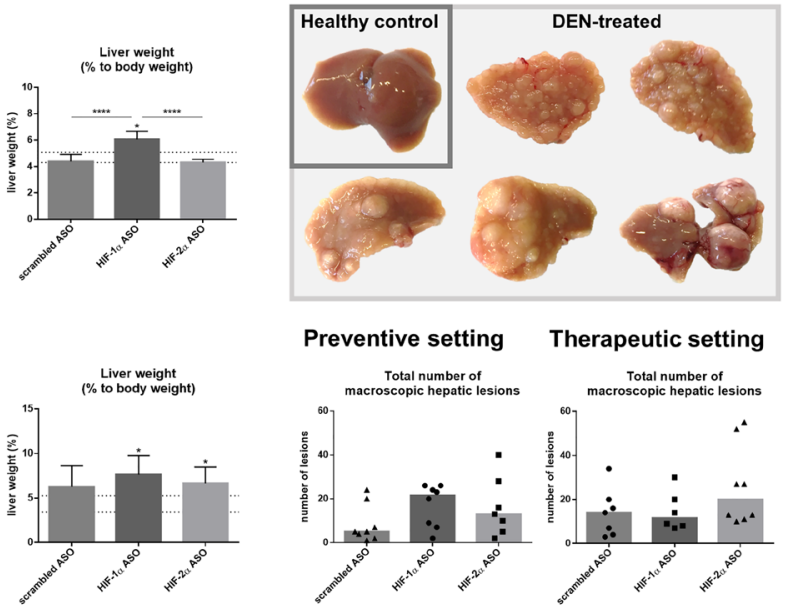

C
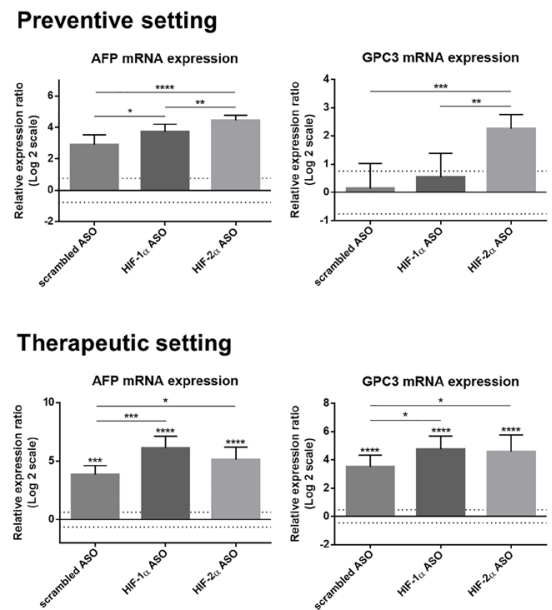


DEN-induced HCC mice. HCC was induced by weekly intraperitoneal DEN injection for 25 weeks. Control mice received weekly intraperitoneal $0.9 \% \mathrm{NaCl}$ injection. DEN-treated mice were intraperitoneally injected with $20 \mathrm{mg} / \mathrm{kg} \mathrm{HIF}-1 \alpha$ ASO, HIF-2 $\alpha$ ASO or scrambled ASO twice per week, in either a preventive or a therapeutic setting. Control mice received scrambled ASO for the same duration of the experiment. (A) Body weight and relative liver weight (expressed as \% to body weight) following preventive and therapeutic treatment. The upper and lower dashed lines represent mean $\pm \mathrm{SD}$ of the control mice. Bars represent mean $\pm \mathrm{SD}$ of different treatment groups of DEN-treated mice ( $n=6-8$ per treatment group). (B) Upper part: Hepatic tissue of healthy control mice and DEN-treated mice. Lower part: Total number of macroscopic hepatic lesions following preventive and therapeutic treatment. Data are represented as individual values with the median ( $n=6-8$ per treatment group). (C) Hepatic mRNA expression of the HCC tumor markers AFP and GPC3 following preventive and therapeutic treatment. The upper and lower dashed lines represent log2-transformed mean $\pm \mathrm{SD}$ of the control mice. Bars represent $\log 2$-transformed mean $\pm \mathrm{SD}$ of different treatment groups of DEN-treated mice, relative to the log2-transformed mean of the control mice ( $n=7-9$ per treatment group). ${ }^{*} p<0.05,{ }^{* *} p<0.01,{ }^{* * *} p<0.001$ and ${ }^{* * * *} p<0.0001$. 
an advanced stage, at which current treatment options are limited and unsatisfactory $[3,5,29]$. Therefore, promising novel therapeutic targets need to be explored [7]. As the HIF pathway regulates multiple cancer hallmarks and consequently has a key role in shaping the HCC TME, targeting this hypoxic response pathway represents an attractive strategy for HCC treatment. To date, only a small portion of HIF pathway-targeting compounds has moved beyond the preclinical stage. A common and important limitation is the lack of specificity towards a certain HIF isoform $[13,15]$. Therefore, this study aimed to explore the therapeutic potential of isoform-specific HIF pathway targeting by means of selective HIF- $1 \alpha$ and HIF-2 $\alpha$ ASOs. In addition to their effect on HCC development and progression, the influence on the inflammatory and fibrotic component of the TME was assessed. In our study, HIF $\alpha$ ASO treatment selectively downregulated its target gene, but did not exert a beneficial effect on hepatocarcinogenesis, induced a pro-inflammatory TME and aggravated fibrosis in the liver of DEN-induced HCC mice.

Three HIF $\alpha$ isoforms (HIF-1 $\alpha$, HIF- $2 \alpha$ and HIF-3 $\alpha$ ) have been described so far [30]. Increased expression of both HIF- $1 \alpha$ and HIF- $2 \alpha$ has been observed in several chronic liver diseases, including alcoholic liver disease (ALD), NAFLD and HCC [31]. Especially HIF-1 $\alpha$ expression has been shown to be positively correlated with poor prognosis, tumor grade, metastasis and lower overall survival rate $[15,31-32]$. The observed upregulation of HIF-1 $\alpha$ in HCC mice euthanized 28 weeks following first DEN injection (therapeutic setting), compared to mice that were euthanized three weeks earlier (preventive setting), along with the increased number of macroscopic tumoral lesions, indeed indicates that HIF- $1 \alpha$ expression increases in advanced HCC. The contribution of HIF- $2 \alpha$ in HCC pathogenesis is less clear, as both tumor promoting and
Percentage of Kupffer cells

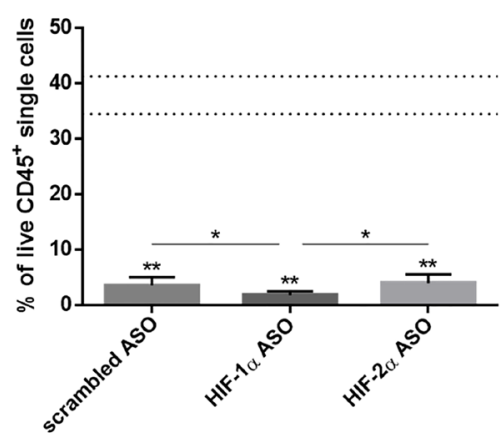

Number of Kupffer cells

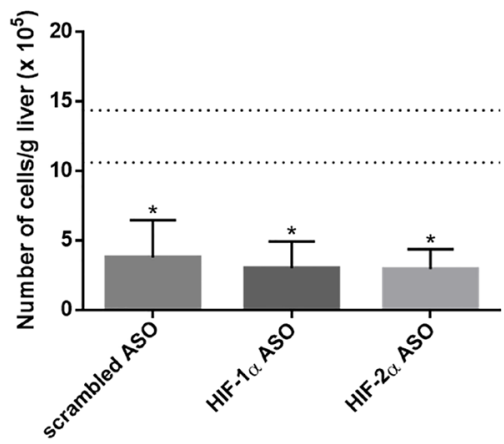

Percentage of monocytes

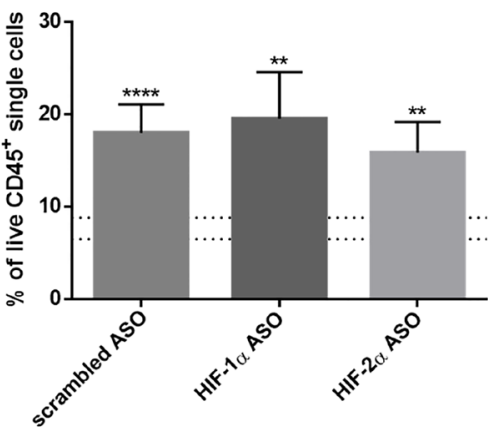

Number of monocytes

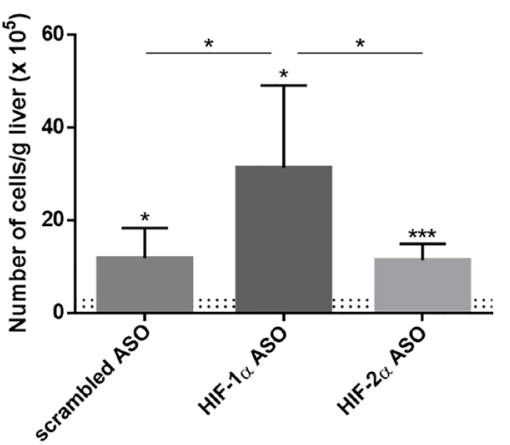

Percentage of monocyte-derived macrophages

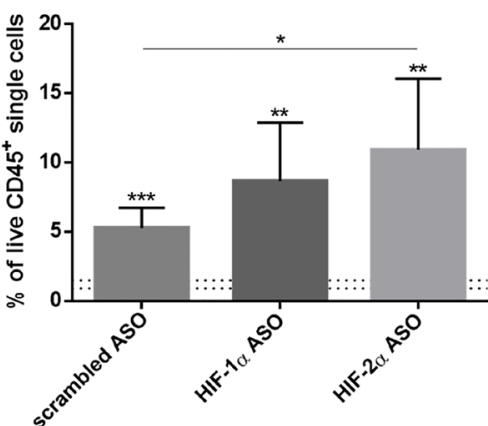

Number of monocyte-derived macrophages

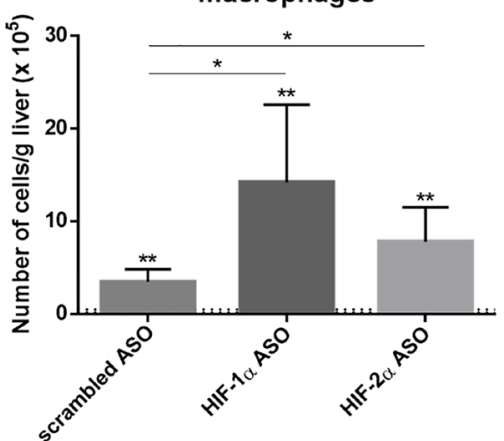

Figure 5: Effect of therapeutic HIF-1 $\alpha$ and HIF-2 $\alpha$ ASO treatment on hepatic macrophage pool in DEN-induced HCC mice. HCC was induced by weekly intraperitoneal DEN injection for 25 weeks. Control mice received weekly intraperitoneal $0.9 \%$ $\mathrm{NaCl}$ injection. DEN-treated mice were intraperitoneally injected with $20 \mathrm{mg} / \mathrm{kg} \mathrm{HIF-1} \alpha \mathrm{ASO}$, HIF-2 $\alpha$ ASO or scrambled ASO twice per week, in a therapeutic setting. Control mice received scrambled ASO for the same duration of the experiment. Upper part: Percentage

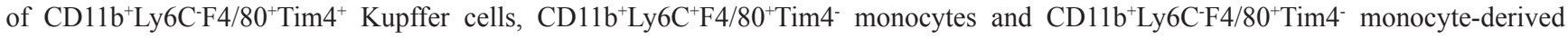
macrophages in live $\mathrm{CD} 45^{+}$single cell gate following treatment, measured by flow cytometry. The upper and lower dashed lines represent mean \pm SD of the control mice. Bars represent mean \pm SD of different treatment groups of DEN-treated mice $(n=6-7$ per treatment group). ${ }^{*} p<0.05,{ }^{* *} p<0.01,{ }^{* * *} p<0.001$ and ${ }^{* * * *} p<0.0001$. Lower part: Number of live CD $45^{+} \mathrm{CD} 11 \mathrm{~b}^{+}$Ly $6 \mathrm{C}^{-} \mathrm{F} 4 / 80^{+}$Tim4 ${ }^{+} \mathrm{Kupffer}$ cells, $\mathrm{CD}^{2} 5^{+} \mathrm{CD} 11 \mathrm{~b}^{+} \mathrm{Ly} 6 \mathrm{C}^{+} \mathrm{F} 4 / 80^{+}$Tim4- monocytes and $\mathrm{CD} 45^{+} \mathrm{CD} 11 \mathrm{~b}^{+} \mathrm{Ly} 6 \mathrm{C}^{-} \mathrm{F} 4 / 80^{+}$Tim4- monocyte-derived macrophages per gram liver tissue following treatment, measured by flow cytometry. The upper and lower dashed lines represent mean \pm SD of the control mice. Bars represent mean $\pm \mathrm{SD}$ of different treatment groups of DEN-treated mice ( $n=6-7$ per treatment group). ${ }^{*} p<0.05,{ }^{* * *} p<0.01,{ }^{* * *} p<0.001$ and ${ }^{* * * *} p<0.0001$. 
tumor suppressing results have been published [31, 32]. Observed discrepancies in the involvement of HIF-1 $\alpha$ and HIF-2 $\alpha$ in HCC development and progression can be explained by the fact that, in addition to a substantial overlap of target genes, they each also regulate a distinct set of genes [30, 32].

A dose-finding study was set up in order to define the optimal dosage regimen of the isoform-specific HIF $\alpha$ ASOs. Both HIF $\alpha$ ASOs selectively downregulate mRNA expression of their respective target gene. Only for HIF-2 $\alpha$ ASO treatment, dose increase above
$20 \mathrm{mg} / \mathrm{kg}$ resulted in more effective HIF-2 $\alpha$ mRNA downregulation. Furthermore, for both HIF $\alpha$ ASOs, the $100 \mathrm{mg} / \mathrm{kg}$ dosage regimen resulted in significant hepatomegaly and upregulation of the mRNA expression of several inflammation-associated markers, including TNF $\alpha$, VCAM-1, CCR2, CCL2 and CXCL2, compared to lower dosage regimens, indicating dose-dependent hepatotoxicity. Consequently, based on its efficacy and safety, we opted for a dosage regimen of $20 \mathrm{mg} / \mathrm{kg}$ twice per week, for both HIF-1 $\alpha$ and HIF-2 $\alpha$ ASO, in subsequent experiments.

\section{Preventive setting}
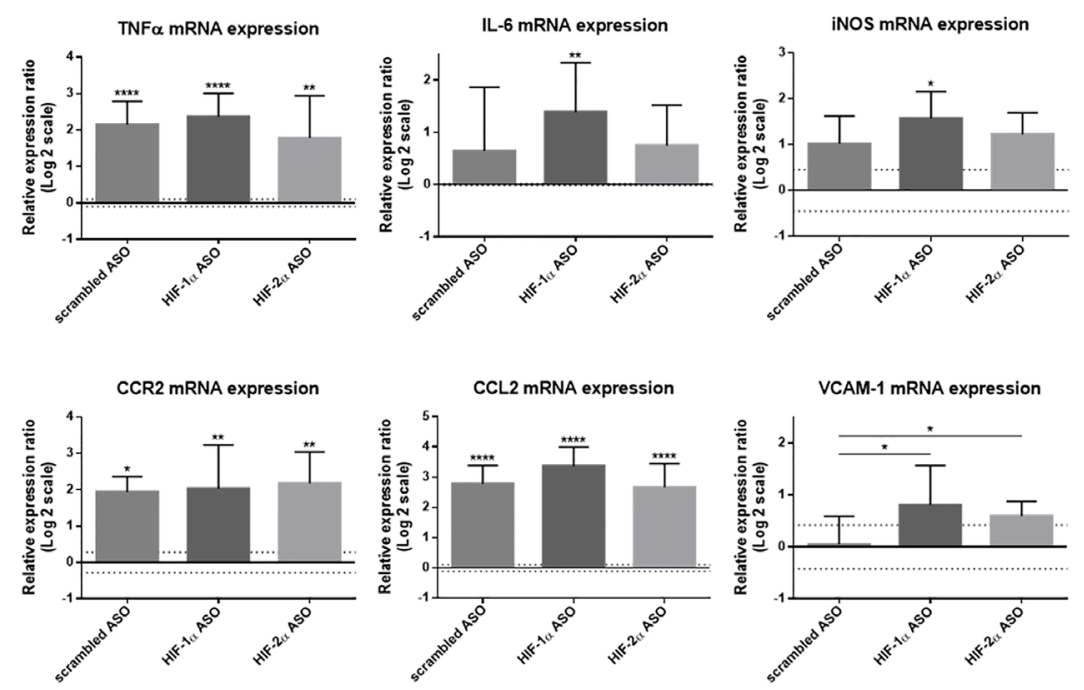

\section{Therapeutic setting}
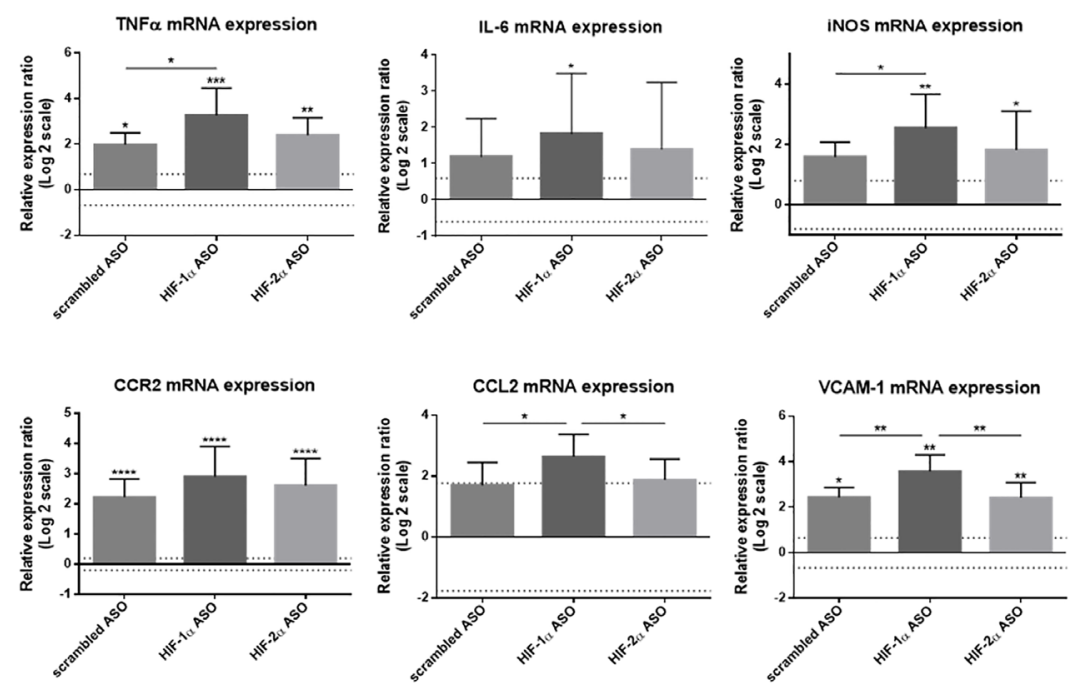

Figure 6: Effect of preventive and therapeutic HIF-1 $\alpha$ and HIF-2 $\alpha$ ASO treatment on hepatic mRNA expression of inflammatory markers in DEN-induced HCC mice. HCC was induced by weekly intraperitoneal DEN injection for 25 weeks. Control mice received weekly intraperitoneal $0.9 \% \mathrm{NaCl}$ injection. DEN-treated mice were intraperitoneally injected with $20 \mathrm{mg} / \mathrm{kg} \mathrm{HIF}-$ $1 \alpha$ ASO, HIF-2 $\alpha$ ASO or scrambled ASO twice per week, in either a preventive or a therapeutic setting. Control mice received scrambled ASO for the same duration of the experiment. Hepatic mRNA expression of several inflammatory markers following preventive and therapeutic treatment is shown. The upper and lower dashed lines represent log2-transformed mean $\pm \mathrm{SD}$ of the control mice. Bars represent $\log 2$-transformed mean $\pm \mathrm{SD}$ of different treatment groups of DEN-treated mice, relative to the log2-transformed mean of the control mice ( $n=7-9$ per treatment group). ${ }^{*} p<0.05,{ }^{* *} p<0.01,{ }^{* * *} p<0.001$ and ${ }^{* * * *} p<0.0001$. 
In order to investigate the effect of isoformspecific HIFa inhibition on HCC tumorigenesis, a DEN-induced HCC mouse model was employed. This experimental HCC mouse model was selected due to its physiologically relevant TME and immune modifications related to HCC development and progression, as longterm repetitive DEN administration induces both chronic liver inflammation and mild fibrosis [33]. DEN injections resulted in formation of macroscopic hepatic lesions in $100 \%$ of the cases. Tumor formation was associated with upregulated mRNA expression of the established HCC tumor markers AFP and GPC3 [34-35]. Flow cytometric analysis of the hepatic macrophage pool confirmed $\mathrm{KC}$ depletion, simultaneous $\mathrm{Ly} 6 \mathrm{C}^{+}$monocyte infiltration and increased MoMfs $[23,36]$. Hepatic infiltration of immune cells and establishment of a pro-inflammatory TME was

\section{Preventive setting}
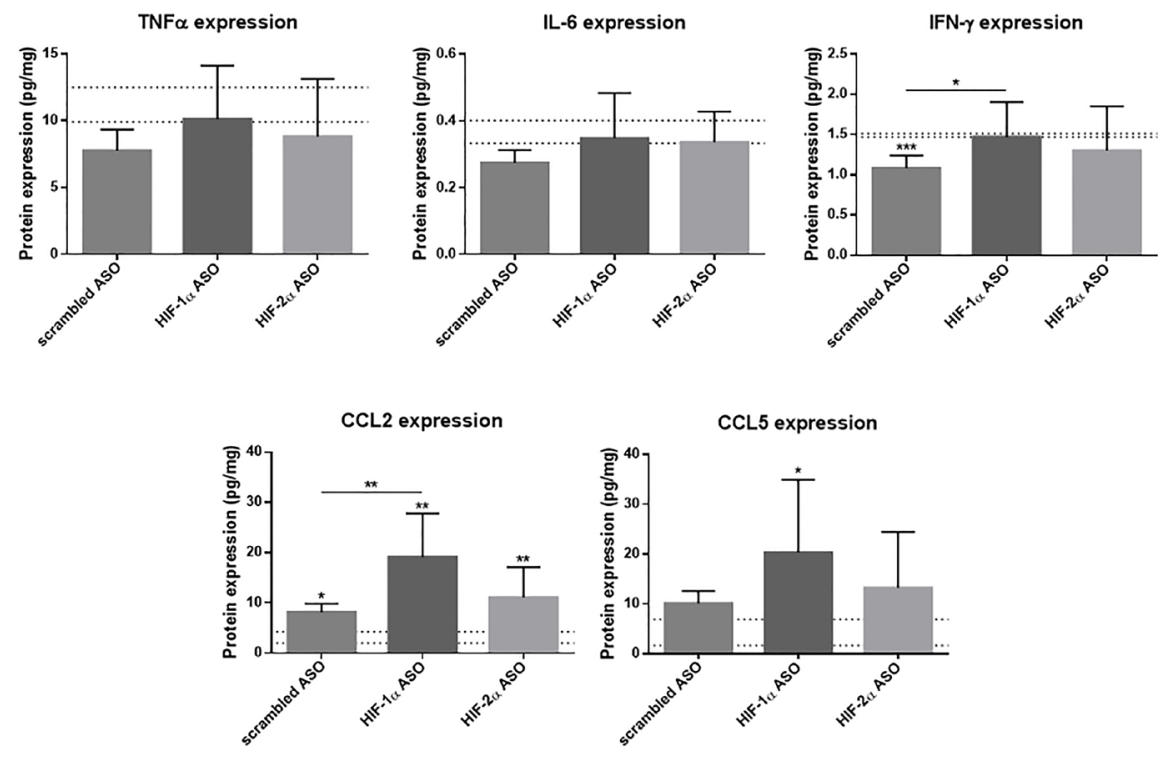

\section{Therapeutic setting}
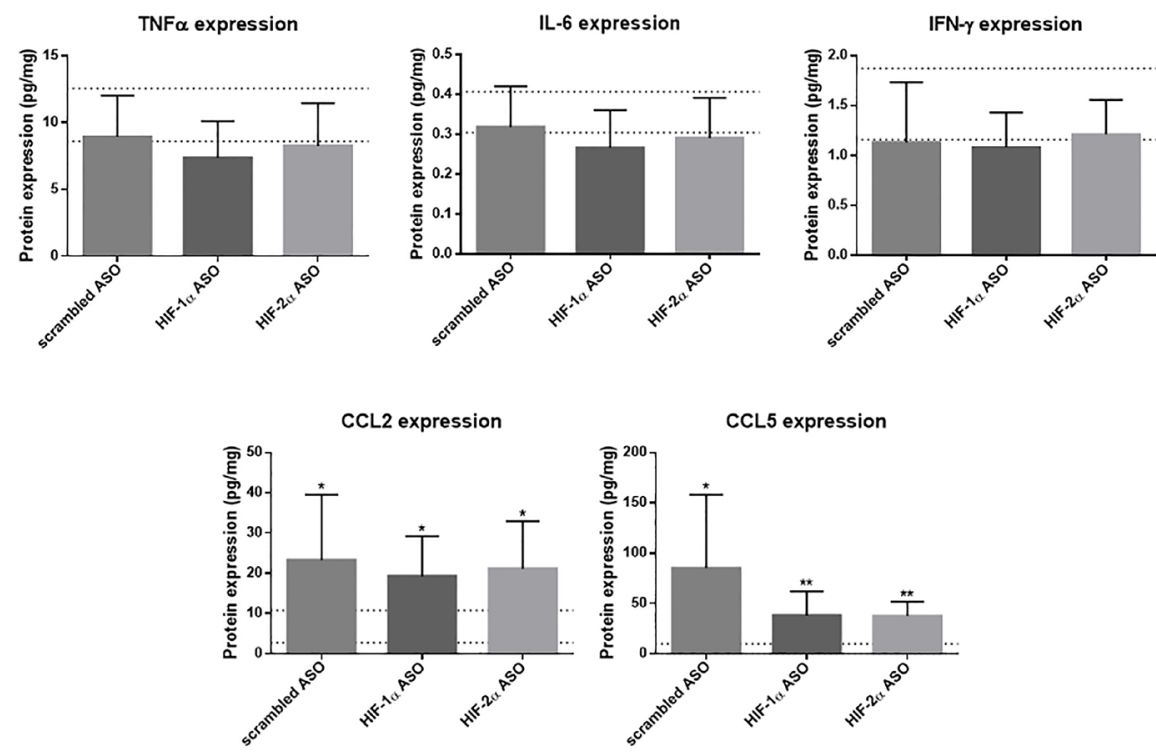

Figure 7: Effect of preventive and therapeutic HIF-1 $\alpha$ and HIF-2 $\alpha$ ASO treatment on hepatic protein expression of inflammatory markers in DEN-induced HCC mice. HCC was induced by weekly intraperitoneal DEN injection for 25 weeks. Control mice received weekly intraperitoneal $0.9 \% \mathrm{NaCl}$ injection. DEN-treated mice were intraperitoneally injected with $20 \mathrm{mg} / \mathrm{kg} \mathrm{HIF}-$ $1 \alpha$ ASO, HIF-2 $\alpha$ ASO or scrambled ASO twice per week, in either a preventive or a therapeutic setting. Control mice received scrambled ASO for the same duration of the experiment. Hepatic protein expression of several inflammatory markers following preventive and therapeutic treatment is shown. The upper and lower dashed lines represent mean $\pm \mathrm{SD}$ of the control mice. Bars represent mean $\pm \mathrm{SD}$ of different treatment groups of DEN-treated mice $\left(n=7-9\right.$ per treatment group). ${ }^{*} p<0.05,{ }^{* *} p<0.01,{ }^{* * *} p<0.001$ and ${ }^{* * * *} p<0.0001$. 
further confirmed via upregulated expression of several inflammatory markers, including TNF $\alpha$, CCR2, CCL2, CCL5 and VCAM-1, at either mRNA or protein level [37-40]. Portal fibrosis without septa (Metavir fibrosis stage F1) was observed in the peritumoral hepatic tissue, in both treatment settings. Furthermore, the observed upregulation of the hepatic mRNA expression of MMP2, MMP-14 and TIMP-1 is in line with the establishment of a fibrotic TME following chronic DEN administration [41-43]. Thus, as the DEN-induced HCC mouse model mimics the human HCC-associated TME in several aspects, it is a suitable experimental HCC model for investigation of the therapeutic potential of our isoformspecific HIF $\alpha$ ASOs.

As macroscopic HCC lesions are only observed following approximately 20 weeks of weekly $35 \mathrm{mg} /$ $\mathrm{kg}$ DEN injections, initiation of HIF $\alpha$ ASO treatment 10 weeks following the first DEN injection enables investigation of its effect on $\mathrm{HCC}$ initiation and development (preventive setting) [26, 44]. Starting HIF $\alpha$ ASO treatment 20 weeks following first DEN administration allows to assess its effect on the progression of HCC (therapeutic setting). As it was the case in the dose-finding study, in both treatment settings, isoform-specific HIF- $1 \alpha$ and HIF-2 $\alpha$ ASO effectively and selectively downregulated hepatic mRNA expression of their target gene. Biometric data however gave some indications of worse general and hepatic condition of the $\mathrm{HIF} \alpha \mathrm{ASO}$-treated mice, as in some treatment groups, relative to the scrambled ASO treatment group, additional weight loss and/or hepatomegaly was observed.

Regarding the effect of specific HIF- $1 \alpha$ and HIF- $2 \alpha$ inhibition on HCC tumorigenesis, preventive treatment did not inhibit or slow down tumor development in our HCC mouse model, as macroscopic lesions were present in $100 \%$ of the ASO-treated mice and furthermore, were more numerous compared to the scrambled ASO treatment group. Moreover, following both preventive and therapeutic HIF- $1 \alpha$ and HIF- $2 \alpha$ ASO treatment, upregulated hepatic mRNA expression of AFP and/ or GPC3 was observed, as compared to scrambled ASO treatment. This finding is supported by previous research which showed that HIF-1 $\alpha$ overexpression downregulates transcriptional activity of the AFP and GPC3 genes in HCC cells, through competition with the oncogenic transcription factor c-Myc [45-46]. Thus, in this case, experimental HIF-1 $\alpha$ inhibition might result in c-Myc-dependent upregulation of AFP and GPC3 mRNA expression. In addition, HIF- $2 \alpha$-mediated inhibition of tumor growth in $\mathrm{HCC}$ has also been previously described [47]. Consequently, the observed absence of beneficial effect of isoform-specific HIF $\alpha$ inhibition on the development of macroscopic HCC lesions, together with upregulated hepatic mRNA expression of $\mathrm{HCC}$

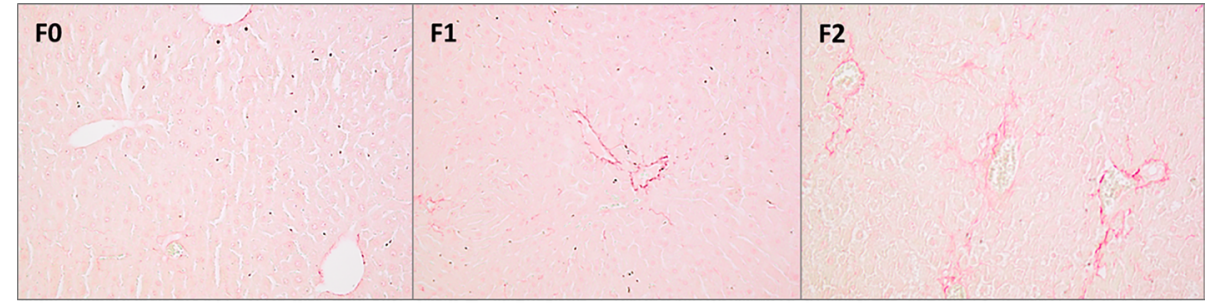

Preventive setting Therapeutic setting


Figure 8: Effect of preventive and therapeutic HIF-1 $\alpha$ and HIF-2 $\alpha$ ASO treatment on liver fibrosis in DEN-induced HCC mice. HCC was induced by weekly intraperitoneal DEN injection for 25 weeks. Control mice received weekly intraperitoneal $0.9 \%$ $\mathrm{NaCl}$ injection. DEN-treated mice were intraperitoneally injected with $20 \mathrm{mg} / \mathrm{kg} \mathrm{HIF}-1 \alpha$ ASO, HIF-2 $\alpha$ ASO or scrambled ASO twice per week, in either a preventive or a therapeutic setting. Control mice received scrambled ASO for the same duration of the experiment. Upper part: Representative histological images of Sirius Red-stained liver sections with Metavir fibrosis stage F0 (no fibrosis), F1 (portal fibrosis without septa) and F2 (portal fibrosis with few septa). Magnification 200×. Lower part: Degree of hepatic fibrosis following preventive and therapeutic treatment, assessed through histological analysis of Sirius Red-stained liver sections using the Metavir scoring system. Data are represented as individual values with the median ( $n=7-9$ per HCC treatment group). 
tumor markers, discourage the use of HIF-1 $\alpha$ and HIF-2 $\alpha$ as targets for the treatment of HCC.

Despite the negative effects of isoform-specific $\mathrm{HIF} \alpha \mathrm{ASO}$ treatment on HCC tumorigenesis in the DENinduced HCC mouse model, it is of great importance to create a better understanding of the distinct influences the different HIF $\alpha$ isoforms exert on the HCC-associated TME. As chronic inflammation and fibrosis are two major features of human $\mathrm{HCC}$, and are shown to play an essential role in its development and progression, we also investigated the effect of isoform-specific HIF $\alpha$ inhibition on both the inflammatory and fibrotic component of the TME associated with experimental DEN-induced HCC $[48,49]$.

Both HIF- $1 \alpha$ and HIF-2 $\alpha$ have been demonstrated to play essential roles in monocyte recruitment and macrophage differentiation in many cancers, including HCC [37, 50-52]. However, in our HCC model, isoformspecific $\mathrm{HIF} \alpha$ inhibition resulted in increased $\mathrm{Ly}_{6} \mathrm{C}^{+}$ monocyte infiltration and/or MoMf differentiation. The

\section{Preventive setting}



MMP-14 mRNA expression



Therapeutic setting
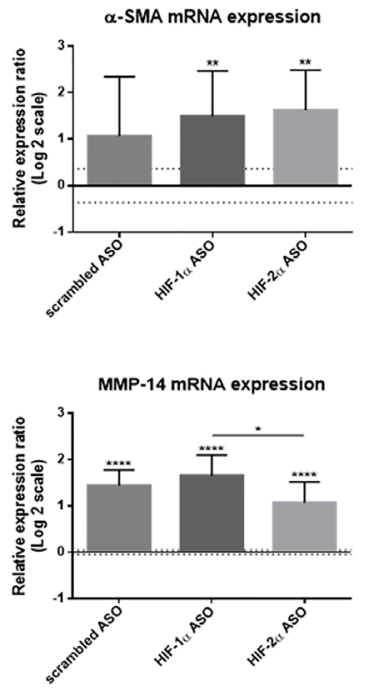
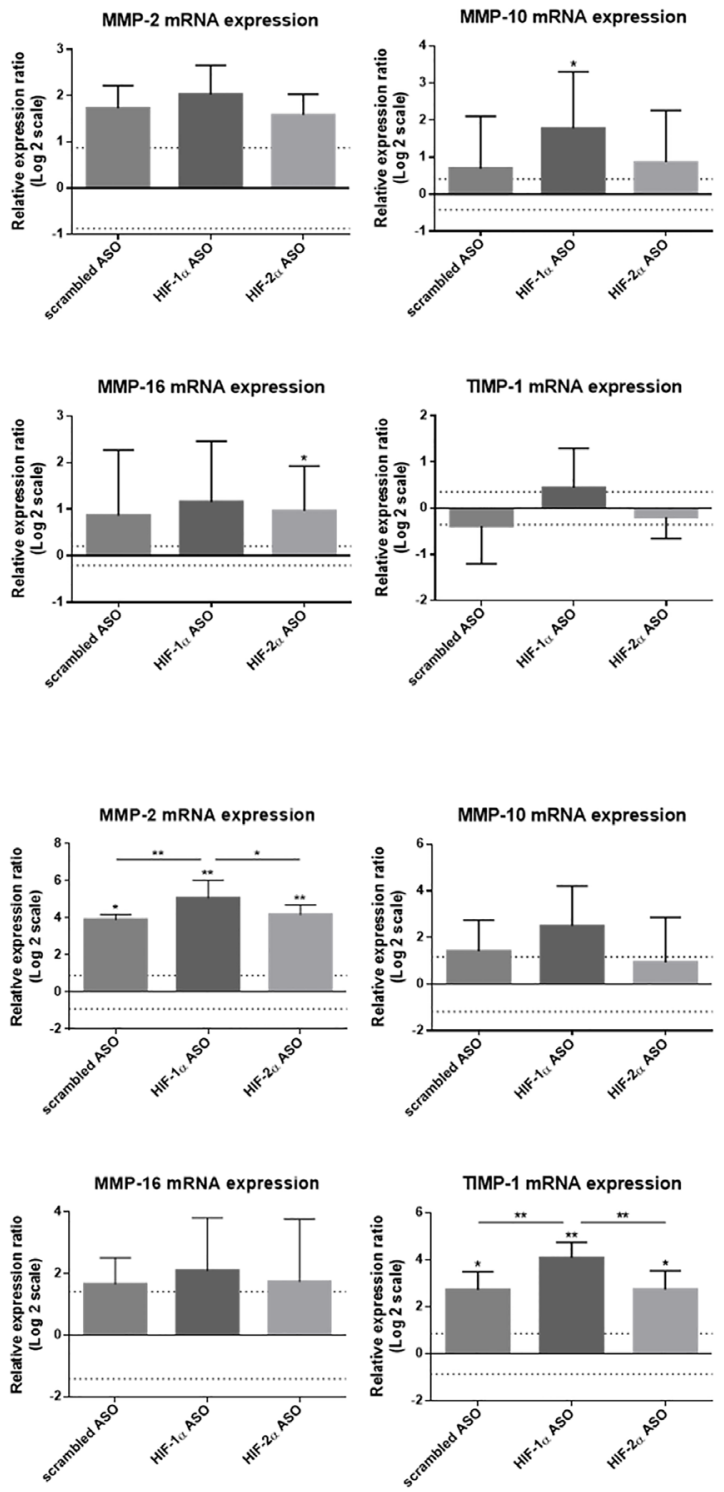

Figure 9: Effect of preventive and therapeutic HIF-1 $\alpha$ and HIF-2 $\alpha$ ASO treatment on fibrotic markers in the liver of DEN-induced HCC mice. HCC was induced by weekly intraperitoneal DEN injection for 25 weeks. Control mice received weekly intraperitoneal $0.9 \% \mathrm{NaCl}$ injection. DEN-treated mice were intraperitoneally injected with $20 \mathrm{mg} / \mathrm{kg} \mathrm{HIF}-1 \alpha$ ASO, HIF-2 $\alpha$ ASO or scrambled ASO twice per week, in either a preventive or a therapeutic setting. Control mice received scrambled ASO for the same duration of the experiment. Hepatic mRNA expression of fibrotic markers following preventive and therapeutic treatment is shown. The upper and lower dashed lines represent log2-transformed mean \pm SD of the control mice. Bars represent log2-transformed mean \pm SD of different treatment groups of DEN-treated mice, relative to the log2-transformed mean of the control mice $\left(n=7-9\right.$ per treatment group). ${ }^{*} p<0.05$, ${ }^{* *} p<0.01,{ }^{* * *} p<0.001$ and ${ }^{* * * *} p<0.0001$. 
pro-inflammatory effect of HIF $\alpha$ inhibition on the HCC TME was further demonstrated by upregulated hepatic mRNA and/or protein expression of several inflammationrelated markers, namely the pro-inflammatory cytokines TNF $\alpha$, IL- 6 and IFN- $\gamma$, the M1-like macrophage marker iNOS, and the immune cell infiltration-related markers CCL2, CCL5 and VCAM-1.

Both HIF- $1 \alpha$ and HIF- $2 \alpha$ transcriptional activity have also been demonstrated to directly or indirectly contribute to fibrogenesis [24, 31, 53, 54]. However, in both treatment settings, isoform-specific HIF $\alpha$ inhibition resulted in an increased extent of fibrosis in the peritumoral hepatic tissue. This pro-fibrotic effect of HIF $\alpha$ inhibition on the HCC TME was further demonstrated by upregulated hepatic mRNA expression of several fibrotic markers, namely $\alpha$-SMA, MMP-2, MMP-10, MMP-14, MMP-16 and/or TIMP-1.

The observed negative effects of both isoformspecific HIF- $1 \alpha$ and HIF-2 $\alpha$ ASO treatment on HCC tumorigenesis in our DEN-induced HCC mouse model, discourage the use of HIF- $1 \alpha$ and HIF- $2 \alpha$ as targets for the treatment of HCC. Furthermore, the pro-inflammatory and pro-fibrotic effects on the HCC TME also raise questions about the use of HIF $\alpha$ ASOs, in the dosing regimen we have investigated, in other cancers, with respect to potential hepatotoxicity. Further preclinical studies testing dosing strategies might indicate if lower doses of isoformspecific HIF $\alpha$ ASOs can be used without potential harm and might be of interest as anti-cancer therapy.

\section{MATERIALS AND METHODS}

\section{Animals}

Male wild type 129/Sv mice were purchased from Janvier Labs (Le Genest-Saint-Isle, France) at 4 weeks of age and housed in open cages in a temperature-controlled room at $20^{\circ} \mathrm{C}$ with a 12 hour light/dark cycle at the laboratory animal facility of the Faculty of Medicine and Health Sciences (Ghent University, Ghent, Belgium). Mice were given ad libitum access to food (mouse maintenance chow; Carfil Quality - Labofood, Oud-Turnhout, Belgium) and water. Mice were acclimatized under controlled conditions for one week prior to the experiments. All mice received care in accordance with the "Guide for the Care and Use of Laboratory Animals" and the Belgian national guidelines for animal protection. HCC was induced at the age of 5 weeks via weekly intraperitoneal injections of $35 \mathrm{mg} / \mathrm{kg}$ DEN (Sigma-Aldrich, Machelen, Belgium), dissolved in $0.9 \%$ sodium chloride ( $\mathrm{NaCl}$; B. Braun, Machelen, Belgium) for 25 weeks. Control mice received weekly intraperitoneal injections of $0.9 \% \mathrm{NaCl}$. Mice were monitored for weight loss and other external signs of disease or discomfort. This study was approved by the Ethical Committee of Experimental Animals at the Faculty of Medicine and Health Sciences of Ghent University (ECD 18/125).

\section{Dose-finding study}

In order to define the optimal dosage regimen of the isoform-specific ASOs used in our preventive and therapeutic studies, 8-week-old male wild type 129/Sv mice were intraperitoneally injected twice per week for 2 weeks with 10,20 or $100 \mathrm{mg} / \mathrm{kg} \mathrm{HIF}-1 \alpha$ ASO, 10, 20 or $100 \mathrm{mg} / \mathrm{kg}$ HIF-2 $\alpha$ ASO, or $20 \mathrm{mg} / \mathrm{kg}$ scrambled ASO (all provided by Ionis Pharmaceuticals, Carlsbad, California, USA), dissolved in phosphate-buffered saline (PBS; Gibco, Thermo Fisher Scientific, Merelbeke, Belgium). Afterwards, mice were sacrificed, the liver was isolated (see "Tissue sampling") and expression of the different $\mathrm{HIF} \alpha$ isoforms and several inflammatory markers was analyzed via quantitative reverse transcription-polymerase chain reaction (RT-qPCR).

\section{Preventive and therapeutic treatment}

DEN-treated mice were intraperitoneally injected twice per week with $20 \mathrm{mg} / \mathrm{kg}$ HIF-1 $\alpha$ ASO, HIF-2 $\alpha$ ASO or scrambled ASO, dissolved in PBS, in either a preventive or therapeutic setting. In the preventive setting, ASO injections started 10 weeks after the first DEN injection (at 15 weeks of age) and persisted for a period of 15 weeks. In the therapeutic setting, ASO injections started 20 weeks after the first DEN injection (at 25 weeks of age) and persisted 8 weeks. These treatment regimens are based on previous publications reporting HCC development by weekly DEN injections $[26,44]$. Control mice received intraperitoneal injections of scrambled ASO twice per week. Following treatment, mice were sacrificed and the liver was divided for further analyses (Figure 10).

\section{Tissue sampling}

Mice were anesthetized via intraperitoneal injection of ketamine $(60 \mathrm{mg} / \mathrm{kg}$; Dechra Veterinary Products, Lille, Belgium) and xylazine (6 mg/kg; Kela, Sint-Niklaas, Belgium), and euthanized by cervical dislocation. Two pieces of the liver were isolated; one was fixed in 4\% phosphate-buffered formaldehyde solution (Klinipath, Olen, Belgium) for histological analysis, and one was incubated in RNAlater (Ambion, Thermo Fisher Scientific), snap frozen in liquid nitrogen and stored at $-80^{\circ} \mathrm{C}$ until further processing for RTqPCR. In mice belonging to the therapeutic treatment groups, the remaining liver was perfused with PBS, isolated, weighed, chopped into small pieces, further dissociated using gentleMACS Dissociator (Miltenyi Biotec, Leiden, The Netherlands), and incubated for 20 minutes in $1 \mathrm{mg} / \mathrm{mL}$ Collagenase A (Sigma-Aldrich) and $300 \mu \mathrm{g} / \mathrm{mL}$ DNase I (Roche Diagnostics, Machelen, Belgium), dissolved in $3 \mathrm{~mL}$ Roswell Park Memorial Institute medium (RPMI; Gibco), in a shaking heated bath $\left(37^{\circ} \mathrm{C}\right)$. Obtained cell suspensions were filtered, 
red blood cells (RBCs) were removed by means of RBC Lysis Buffer (composed of $155 \mathrm{mM} \mathrm{NH}_{4} \mathrm{Cl}, 12 \mathrm{mM}$ $\mathrm{NaHCO}_{3}$ and $0.1 \mathrm{mM}$ EDTA) and cells were stained with appropriate antibodies for flow cytometry. During sacrification, mice were weighed, whole-liver weights were recorded, and the number of hepatic lesions was macroscopically evaluated. Large tumoral lesions were removed from the pieces of liver used for downstream analysis.

\section{Flow cytometry}

Cells were prestained with a 1:100 dilution of Zombie Aqua (Fixable Viability Dye; BioLegend, London, UK) for 20 minutes at $4^{\circ} \mathrm{C}$ in the dark. After 10 minutes, an equal volume of a 1:100 dilution of TruStain FcX PLUS (anti-mouse CD16/32 antibody) and TrueStain Monocyte Blocker (BioLegend) was added. After a washing step, cells were stained with CD3e-PerCPCy5.5, CD19-PerCP-Cy5.5 (eBioscience, Thermo Fisher Scientific), NK1.1-PerCP-Cy5.5, CD103-PerCP-Cy5.5, F4/80-FITC, Ly6G-BV785, Ly6C-BV650 (BioLegend), SiglecF-PerCP-Cy5.5, CD45-APC-Cy7, CD11b-PECy7 and Tim4-PE (BD Biosciences, Erembodegem, Belgium) for 20 minutes at $4{ }^{\circ} \mathrm{C}$ in the dark. Cells were analyzed with a BD FACSAria Fusion flow cytometer (BD Biosciences) and FlowJo software (FlowJo LLC, BD Biosciences), and gated first as live $\mathrm{CD} 45^{+}$single cells. Subsequently, CD $3 \mathrm{e}^{+}, \mathrm{CD} 19^{+}, \mathrm{NK} 1.1^{+}, \mathrm{CD} 103^{+}$and SiglecF ${ }^{+}$cells were eliminated, and $\mathrm{CD} 11 \mathrm{~b}^{+} \mathrm{Ly}_{6 \mathrm{C}^{+}} \mathrm{Ly}_{6 \mathrm{G}^{-}}$ monocytes, CD11b+Ly6C-F4/80+Tim4 ${ }^{+}$Kupffer cells (KCs) and CD11b ${ }^{+}$Ly6C-F4/80+Tim4- monocyte-derived macrophages (MoMfs) were gated.

\section{RT-qPCR}

RNA was extracted from $20 \mathrm{mg}$ of frozen liver tissue preserved in RNAlater, according to the instruction manual of the Aurum Total RNA Mini Kit (Bio-Rad Laboratories, Temse, Belgium), and measured for purity and quantity by spectrophotometry (NanoDrop; Thermo Fisher Scientific). cDNA was obtained from one microgram of RNA by reverse transcription using the SensiFAST cDNA Synthesis Kit (Bioline, London, UK) according to the manufacturer's guidelines. Diluted cDNA (1:10) was subjected to 45 cycles of quantitative PCR amplification using SYBR Green mix (SensiMix; Bioline) and $2 \mu \mathrm{M}$ of each primer (Biolegio, Nijmegen, The Netherlands). A 2-step program was run on a LightCycler 480 (Roche Diagnostics). Melting curve analysis confirmed primer specificities. All reactions were run in duplicate and normalized to reference genes that showed stable expression in all samples: hydroxymethylbilane synthase (HMBS), hypoxanthineguanine phosphoribosyltransferase (HPRT) and succinate dehydrogenase complex flavoprotein subunit A (SDHA). The PCR efficiency of each primer pair was calculated using a standard curve of reference cDNA. Amplification efficiency was determined using the formula $10^{-1 / \text { slope }}-1$. The sequences of the used primer pairs are listed in Supplementary Table 1.

\section{Multiplex analyses of pro-inflammatory cytokines/chemokines}

Snap-frozen liver tissue was thawed in $1 \mathrm{mg} / \mathrm{mL}$ protease inhibitor cocktail (cOmplete, Mini, EDTA-free

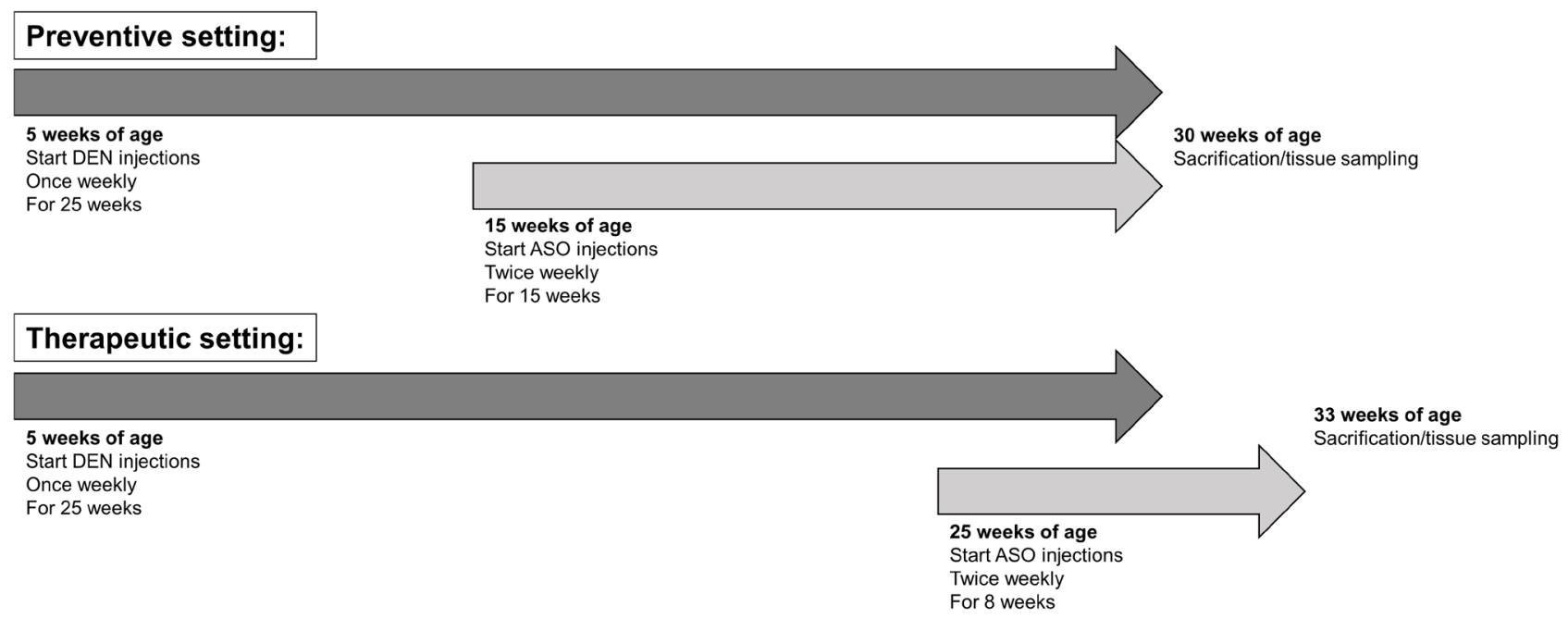

Figure 10: Preventive and therapeutic treatment of ASOs in experimental HCC. HCC was induced by weekly intraperitoneal DEN injection for 25 weeks. Control mice received weekly intraperitoneal $0.9 \% \mathrm{NaCl}$ injection. DEN-treated mice were intraperitoneally injected with $20 \mathrm{mg} / \mathrm{kg} \mathrm{HIF-1} \alpha$ ASO, HIF-2 $\alpha$ ASO or scrambled ASO twice per week. In the preventive setting, ASO injections started 10 weeks following the first DEN injection (at 15 weeks of age) and persisted for a period of 15 weeks. In the therapeutic setting, ASO injections started 20 weeks following the first DEN injection (at 25 weeks of age) and persisted for a period of 8 weeks. Control mice received scrambled ASO for the same duration of the experiment. Following respective treatment periods, mice were sacrificed and the liver was isolated for further analyses. 
Protease Inhibitor Cocktail; Roche Diagnostics), 1 vol\% phosphatase inhibitor cocktail 2 (Sigma-Aldrich) and 1 vol\% phosphatase inhibitor cocktail 3 (Sigma-Aldrich) in PBS, lysed by sonication and centrifuged (15 minutes, $\left.15,000 \mathrm{rpm}, 4^{\circ} \mathrm{C}\right)$. The supernatant was stored at $-80^{\circ} \mathrm{C}$ until further analysis. Total protein concentrations were measured using the Pierce BCA Protein Assay Kit (Thermo Fisher Scientific) according to the manufacturer's guidelines. Protein levels of TNF $\alpha$, IL-6, IFN- $\gamma$, CCL2 and CCL5 were determined by a bead-based Bio-Plex multiplex immunoassay (Bio-Rad Laboratories) according to the manufacturer's guidelines.

\section{Histology}

Liver samples were fixed in $4 \%$ phosphatebuffered formaldehyde solution, dehydrated, embedded in paraffin, and sectioned ( $5 \mu \mathrm{m}$ sections). Liver sections were stained with Sirius Red (Sigma-Aldrich). The extent of fibrosis was visualized using an Olympus BX41 microscope (Olympus, Antwerp, Belgium) and Cell^D software (Olympus), and scored using the Metavir scoring system. The scoring was carried out by two independent researchers, who were blinded to the study samples.

\section{Statistical analysis}

Statistical analysis was performed using GraphPad Prism 6 (GraphPad Software, San Diego, California, USA). Normality was evaluated with the D'Agostino-Pearson omnibus test. Outliers were identified with the ROUT method, and excluded from the datasets. The maximum allowed false discovery rate was set to $1 \%$. Normally distributed data were analyzed with the Student's $t$-test or one-way analysis of variance (ANOVA) corrected with the Holm-Sidak test. Non-normally distributed data were analyzed using the Mann-Whitney $U$ test or the KruskalWallis test corrected with Dunn's multiple comparisons test. RT-qPCR data are expressed as log2-transformed mean \pm SD relative to the log2-transformed mean of the control. Other measurements are expressed as median or mean \pm SD. Twotailed $p$-values $<0.05$ were considered statistically significant $\left({ }^{*} p<0.05,{ }^{* *} p<0.01,{ }^{* * *} p<0.001\right.$ and $\left.{ }^{* * * *} p<0.0001\right)$.

\section{Abbreviations}

$\alpha$-SMA: $\alpha$-smooth muscle actin; AFP: $\alpha$-fetoprotein; AKT: protein kinase B; ALD: alcoholic liver disease; ANOVA: analysis of variance; ASO: antisense oligonucleotide; CBP: CREB-binding protein; CCL: C-C motif chemokine ligand; $\mathrm{CCR}$ : $\mathrm{C}-\mathrm{C}$ motif chemokine receptor; CTLA-4: cytotoxic T-lymphocyte-associated protein 4; CXCL: C-X-C motif chemokine ligand; DEN: N:N-diethylnitrous amide; ECM: extracellular matrix; EPO: erythropoietin; FIH: factor inhibiting HIF; GAPDH: glyceraldehyde 3-phosphate dehydrogenase;
GLUT1: glucose transporter 1; GPC3: glypican-3; HCC: hepatocellular carcinoma; HDAC: histone deacetylase; HIF: hypoxia-inducible factor; HMBS: hydroxymethylbilane synthase; HPRT: hypoxanthineguanine phosphoribosyltransferase; HRE: hypoxia response element; Hsp90: heat shock protein 90; IFN: interferon; IGF-2: insulin-like growth factor 2; IL: interleukin; iNOS: inducible nitric oxide synthase; IRE: iron-responsive element; IRP1: iron-regulatory protein 1; KC: Kupffer cell; LOX: lysyl oxidase; MMP: matrix metalloproteinase; MoMf: monocyte-derived macrophage; mRNA: messenger ribonucleic acid; mTOR: mammalian target of rapamycin; $\mathrm{NaCl}$ : sodium chloride; NAFLD: non-alcoholic fatty liver disease; PBS: phosphate-buffered saline; PD-1: programmed cell death protein 1; PDGF: platelet-derived growth factor; PGK1: phosphoglycerate kinase 1; PHD: prolyl hydroxylase domain-containing protein; PI3K: phosphoinositide 3-kinase; pVHL: von Hippel-Lindau tumor suppressor protein; RBC: red blood cell; RPMI: Roswell Park Memorial Institute medium; RT-qPCR: quantitative reverse transcriptionpolymerase chain reaction; SDHA: succinate dehydrogenase complex flavoprotein subunit A; TGF: transforming growth factor; TIMP: tissue inhibitor of metalloproteinase; TME: tumor microenvironment; TNF: tumor necrosis factor; VCAM: vascular cell adhesion molecule; VEGF: vascular endothelial growth factor; VEGFR: vascular endothelial growth factor receptor.

\section{Author contributions}

BV and LD conceptualized and designed the study; BV, KDM, SL performed the experiments and analyzed the data; AG, XV, HVV and LD supervised the study; BV and LD drafted the manuscript; all authors reviewed the manuscript and approved the final version; HVV and LD acquired funding for the study.

\section{ACKNOWLEDGMENTS}

The authors thank Petra Van Wassenhove, Astrid Vandierendonck, Sanne Van Campenhout (Hepatology Research Unit), Els Van Deynse, Inge Van Colen and Eva Gijbels (Gut-Liver Immunopharmacology Unit) for their technical assistance. HIF- $1 \alpha$ and HIF- $2 \alpha$ ASO were kindly provided by Ionis Pharmaceuticals.

\section{CONFLICTS OF INTEREST}

The authors have no conflicts of interest to declare.

\section{FUNDING}

This research was funded by Stand Up to CancerThe Flemish Cancer Society (Kom op tegen Kanker). 


\section{REFERENCES}

1. Yang JD, Hainaut P, Gores GJ, Amadou A, Plymoth A, Roberts LR. A global view of hepatocellular carcinoma: trends, risk, prevention and management. Nat Rev Gastroenterol Hepatol. 2019; 16:589-604. https://doi. org/10.1038/s41575-019-0186-y. [PubMed]

2. Villanueva A. Hepatocellular Carcinoma. N Engl J Med. 2019; 380:1450-62. https://doi.org/10.1056/ NEJMra1713263. [PubMed]

3. Balogh J, Victor D 3rd, Asham EH, Burroughs SG, Boktour M, Saharia A, Li X, Ghobrial RM, Monsour HP Jr. Hepatocellular carcinoma: a review. J Hepatocell Carcinoma. 2016; 3:41-53. https://doi.org/10.2147/JHC. S61146. [PubMed]

4. Dhanasekaran R, Bandoh S, Roberts LR. Molecular pathogenesis of hepatocellular carcinoma and impact of therapeutic advances. F1000Res. 2016; 5:F1000 Faculty Rev-879. https://doi.org/10.12688/f1000research.6946.1. [PubMed]

5. Forner A, Reig M, Varela M, Burrel M, Feliu J, Briceño J, Sastre J, Martí-Bonmati L, Llovet JM, Bilbao JI, Sangro B, Pardo F, Ayuso C, et al. [Diagnosis and treatment of hepatocellular carcinoma. Update consensus document from the AEEH, SEOM, SERAM, SERVEI and SETH]. Med Clin (Barc). 2016; 146:511.e1-511.e22. https://doi. org/10.1016/j.medcli.2016.01.028. [PubMed]

6. Xu W, Liu K, Chen M, Sun JY, McCaughan GW, Lu XJ, Ji J. Immunotherapy for hepatocellular carcinoma: recent advances and future perspectives. Ther Adv Med Oncol. 2019; 11:1758835919862692. https://doi. org/10.1177/1758835919862692. [PubMed]

7. Neureiter D, Stintzing S, Kiesslich T, Ocker M. Hepatocellular carcinoma: Therapeutic advances in signaling, epigenetic and immune targets. World J Gastroenterol. 2019; 25:3136-50. https://doi.org/10.3748/ wjg.v25.i25.3136. [PubMed]

8. Cassim S, Raymond VA, Dehbidi-Assadzadeh L, Lapierre $\mathrm{P}$, Bilodeau M. Metabolic reprogramming enables hepatocarcinoma cells to efficiently adapt and survive to a nutrient-restricted microenvironment. Cell Cycle. 2018; 17:903-16. https://doi.org/10.1080/15384101.2018.1460023. [PubMed]

9. Cassim S, Raymond VA, Lacoste B, Lapierre P, Bilodeau M. Metabolite profiling identifies a signature of tumorigenicity in hepatocellular carcinoma. Oncotarget. 2018; 9:26868-83. https://doi.org/10.18632/oncotarget.25525. [PubMed]

10. Vander Heiden MG, Cantley LC, Thompson CB. Understanding the Warburg effect: the metabolic requirements of cell proliferation. Science. 2009; 324:1029 33. https://doi.org/10.1126/science.1160809. [PubMed]

11. Vander Heiden MG, DeBerardinis RJ. Understanding the Intersections between Metabolism and Cancer Biology. Cell. 2017; 168:657-69. https://doi.org/10.1016/j. cell.2016.12.039. [PubMed]
12. Hanahan D, Weinberg RA. Hallmarks of cancer: the next generation. Cell. 2011; 144:646-74. https://doi. org/10.1016/j.cell.2011.02.013. [ [PubMed]

13. Guo Y, Xiao Z, Yang L, Gao Y, Zhu Q, Hu L, Huang $\mathrm{D}, \mathrm{Xu}$ Q. Hypoxia-inducible factors in hepatocellular carcinoma (Review). Oncol Rep. 2020; 43:3-15. https:// doi.org/10.3892/or.2019.7397. [PubMed]

14. Lin CA, Chang LL, Zhu H, He QJ, Yang B. Hypoxic microenvironment and hepatocellular carcinoma treatment. Hepatoma Res. 2018; 4:26. https://doi.org/10.20517/2394$\underline{5079.2018 .27 .}$

15. Chen C, Lou T. Hypoxia inducible factors in hepatocellular carcinoma. Oncotarget. 2017; 8:46691-703. https://doi. org/10.18632/oncotarget.17358. [PubMed]

16. Akanji MA, Rotimi D, Adeyemi OS. Hypoxia-Inducible Factors as an Alternative Source of Treatment Strategy for Cancer. Oxid Med Cell Longev. 2019; 2019:8547846. https://doi.org/10.1155/2019/8547846. [PubMed]

17. Dengler VL, Galbraith M, Espinosa JM. Transcriptional regulation by hypoxia inducible factors. Crit Rev Biochem Mol Biol. 2014; 49:1-15. https://doi.org/10.3109/1040923 8.2013.838205. [PubMed]

18. Chowdhury R, Hardy A, Schofield CJ. The human oxygen sensing machinery and its manipulation. Chem Soc Rev. 2008; 37:1308-19. https://doi.org/10.1039/b701676j. [PubMed]

19. Wigerup C, Påhlman S, Bexell D. Therapeutic targeting of hypoxia and hypoxia-inducible factors in cancer. Pharmacol Ther. 2016; 164:152-69. https://doi.org/10.1016/j. pharmthera.2016.04.009. [PubMed]

20. Murugesan T, Rajajeyabalachandran G, Kumar S, Nagaraju S, Jegatheesan SK. Targeting HIF-2 $\alpha$ as therapy for advanced cancers. Drug Discov Today. 2018; 23:1444-51. https://doi.org/10.1016/j.drudis.2018.05.003. [PubMed]

21. Heindryckx F, Kuchnio A, Casteleyn C, Coulon S, Olievier K, Colle I, Geerts A, Libbrecht L, Carmeliet P, Van Vlierberghe H. Effect of prolyl hydroxylase domain-2 haplodeficiency on the hepatocarcinogenesis in mice. J Hepatol. 2012; 57:61-68. https://doi.org/10.1016/j. jhep.2012.02.021. [PubMed]

22. Bogaerts E, Paridaens A, Verhelst X, Carmeliet P, Geerts A, Van Vlierberghe H, Devisscher L. Effect of prolyl hydroxylase domain 2 haplodeficiency on liver progenitor cell characteristics in early mouse hepatocarcinogenesis. EXCLI J. 2016; 15:687-98. https://doi.org/10.17179/ excli2016-607. [PubMed]

23. Lefere S, Degroote H, Van Vlierberghe H, Devisscher L. Unveiling the depletion of Kupffer cells in experimental hepatocarcinogenesis through liver macrophage subtypespecific markers. J Hepatol. 2019; 71:631-33. https://doi. org/10.1016/i.jhep.2019.03.016. [PubMed]

24. Triantafyllou EA, Mylonis I, Simos G, Paraskeva E. Hypoxia Induces Pro-Fibrotic and Fibrosis Marker Genes in Hepatocellular Carcinoma Cells Independently of Inflammatory Stimulation and the NF- $\kappa$ B Pathway. 
Hypoxia (Auckl). 2019; 7:87-91. https://doi.org/10.2147/ HP.S235967. [PubMed]

25. Roth KJ, Copple BL. Role of Hypoxia-Inducible Factors in the Development of Liver Fibrosis. Cell Mol Gastroenterol Hepatol. 2015; 1:589-97. https://doi.org/10.1016/j. jemgh.2015.09.005. [PubMed]

26. Heindryckx F, Mertens K, Charette N, Vandeghinste B, Casteleyn C, Van Steenkiste C, Slaets D, Libbrecht L, Staelens S, Starkel P, Geerts A, Colle I, Van Vlierberghe H. Kinetics of angiogenic changes in a new mouse model for hepatocellular carcinoma. Mol Cancer. 2010; 9:219. https:// doi.org/10.1186/1476-4598-9-219. [PubMed]

27. Ghouri YA, Mian I, Rowe JH. Review of hepatocellular carcinoma: Epidemiology, etiology, and carcinogenesis. J Carcinog. 2017; 16:1. https://doi.org/10.4103/jcar. JCar 9_16. [PubMed]

28. Pocha C, Xie C. Hepatocellular carcinoma in alcoholic and non-alcoholic fatty liver disease-one of a kind or two different enemies? Transl Gastroenterol Hepatol. 2019; 4:72. https://doi.org/10.21037/tgh.2019.09.01. [PubMed]

29. Dimitroulis D, Damaskos C, Valsami S, Davakis S, Garmpis N, Spartalis E, Athanasiou A, Moris D, Sakellariou S, Kykalos S, Tsourouflis G, Garmpi A, Delladetsima I, et al. From diagnosis to treatment of hepatocellular carcinoma: An epidemic problem for both developed and developing world. World J Gastroenterol. 2017; 23:5282-94. https:// doi.org/10.3748/wig.v23.i29.5282. [PubMed]

30. D'Ignazio L, Batie M, Rocha S. Hypoxia and Inflammation in Cancer, Focus on HIF and NF- $\kappa$ B. Biomedicines. 2017; 5:21. https://doi.org/10.3390/biomedicines5020021. [PubMed]

31. Ju C, Colgan SP, Eltzschig HK. Hypoxia-inducible factors as molecular targets for liver diseases. J Mol Med (Berl). 2016; 94:613-27. https://doi.org/10.1007/s00109-0161408-1. [PubMed]

32. Kietzmann T. Liver Zonation in Health and Disease: Hypoxia and Hypoxia-Inducible Transcription Factors as Concert Masters. Int J Mol Sci. 2019; 20:2347. https://doi. org/10.3390/ijms20092347. [PubMed]

33. Macek Jilkova Z, Kurma K, Decaens T. Animal Models of Hepatocellular Carcinoma: The Role of Immune System and Tumor Microenvironment. Cancers (Basel). 2019; 11:1487. https://doi.org/10.3390/cancers11101487. [PubMed]

34. Zhao YJ, Ju Q, Li GC. Tumor markers for hepatocellular carcinoma. Mol Clin Oncol. 2013; 1:593-98. https://doi. org/10.3892/mco.2013.119. [PubMed]

35. Braicu C, Burz C, Berindan-Neagoe I, Balacescu O, Graur F, Cristea V, Irimie A. Hepatocellular Carcinoma: Tumorigenesis and Prediction Markers. Gastroenterology Res. 2009; 2:19199. https://doi.org/10.4021/gr2009.07.1304. [PubMed]

36. Degroote H, Van Dierendonck A, Geerts A, Van Vlierberghe H, Devisscher L. Preclinical and Clinical Therapeutic Strategies Affecting Tumor-Associated Macrophages in Hepatocellular Carcinoma. J Immunol Res. 2018; 2018:7819520. https://doi.org/10.1155/2018/7819520. [PubMed]

37. Capece D, Fischietti M, Verzella D, Gaggiano A, Cicciarelli G, Tessitore A, Zazzeroni F, Alesse E. The inflammatory microenvironment in hepatocellular carcinoma: a pivotal role for tumor-associated macrophages. Biomed Res Int. 2013; 2013:187204. https://doi.org/10.1155/2013/187204. [PubMed]

38. Avila MA, Berasain C. Targeting CCL2/CCR2 in TumorInfiltrating Macrophages: A Tool Emerging Out of the Box Against Hepatocellular Carcinoma. Cell Mol Gastroenterol Hepatol. 2019; 7:293-94. https://doi.org/10.1016/j. jcmgh.2018.11.002. [PubMed]

39. Ho JW, Poon RT, Tong CS, Fan ST. Clinical significance of serum vascular cell adhesion molecule-1 levels in patients with hepatocellular carcinoma. World J Gastroenterol. 2004; 10:2014-18. https://doi.org/10.3748/wig.v10.i14.2014. [PubMed]

40. Mohs A, Kuttkat N, Reißing J, Zimmermann HW, Sonntag R, Proudfoot A, Youssef SA, de Bruin A, Cubero FJ, Trautwein C. Functional role of CCL5/RANTES for HCC progression during chronic liver disease. J Hepatol. 2017; 66:743-53. $\quad$ https://doi.org/10.1016/i.jhep.2016.12.011. [PubMed]

41. Roeb E. Matrix metalloproteinases and liver fibrosis (translational aspects). Matrix Biol. 2018; 68-9:463-73. https://doi.org/10.1016/j.matbio.2017.12.012. [PubMed]

42. Naim A, Pan Q, Baig MS. Matrix Metalloproteinases (MMPs) in Liver Diseases. J Clin Exp Hepatol. 2017; 7:367-72. $\quad$ https://doi.org/10.1016/j.jceh.2017.09.004. [PubMed]

43. Duarte S, Baber J, Fujii T, Coito AJ. Matrix metalloproteinases in liver injury, repair and fibrosis. Matrix Biol. 2015; 44-46:147-56. https://doi.org/10.1016/j. matbio.2015.01.004. [PubMed]

44. Heindryckx F, Colle I, Van Vlierberghe H. Experimental mouse models for hepatocellular carcinoma research. Int J Exp Pathol. 2009; 90:367-86. https://doi.org/10.1111/ j.1365-2613.2009.00656.x. [ [PubMed]

45. Mazure NM, Chauvet C, Bois-Joyeux B, Bernard MA, Nacer-Chérif H, Danan JL. Repression of alpha-fetoprotein gene expression under hypoxic conditions in human hepatoma cells: characterization of a negative hypoxia response element that mediates opposite effects of hypoxia inducible factor-1 and c-Myc. Cancer Res. 2002; 62:115865. [PubMed]

46. Tong Y, Tong K, Zhu Q, Wu Y, Yang Y, Zhang J, Hu P, Yan S. Cobalt Chloride Induced Apoptosis by Inhibiting GPC3 Expression via the HIF-1 $\alpha / \mathrm{c}-\mathrm{Myc}$ Axis in HepG2 Cells. Onco Targets Ther. 2019; 12:10663-70. https://doi. org/10.2147/OTT.S227215. [PubMed]

47. Sun HX, Xu Y, Yang XR, Wang WM, Bai H, Shi RY, Nayar SK, Devbhandari RP, He YZ, Zhu QF, Sun YF, 
Hu B, Khan M, et al. Hypoxia inducible factor 2 alpha inhibits hepatocellular carcinoma growth through the transcription factor dimerization partner 3/E2F transcription factor 1-dependent apoptotic pathway. Hepatology. 2013; 57:1088-97. https://doi.org/10.1002/hep.26188. [PubMed]

48. Yu LX, Ling Y, Wang HY. Role of nonresolving inflammation in hepatocellular carcinoma development and progression. NPJ Precis Oncol. 2018; 2:6. https://doi. org/10.1038/s41698-018-0048-z. [ [PubMed]

49. O'Rourke JM, Sagar VM, Shah T, Shetty S. Carcinogenesis on the background of liver fibrosis: Implications for the management of hepatocellular cancer. World J Gastroenterol. 2018; 24:4436-47. https://doi.org/10.3748/ wjg.v24.i39.4436. [PubMed]

50. Cramer T, Yamanishi Y, Clausen BE, Förster I, Pawlinski R, Mackman N, Haase VH, Jaenisch R, Corr M, Nizet V, Firestein GS, Gerber HP, Ferrara N, Johnson RS. HIF1alpha is essential for myeloid cell-mediated inflammation. Cell. 2003; 112:645-57. https://doi.org/10.1016/s0092$\underline{\text { 8674(03)00154-5. [PubMed] }}$

51. Doedens AL, Stockmann C, Rubinstein MP, Liao D, Zhang N, DeNardo DG, Coussens LM, Karin M, Goldrath AW,
Johnson RS. Macrophage expression of hypoxia-inducible factor-1 alpha suppresses T-cell function and promotes tumor progression. Cancer Res. 2010; 70:7465-75. https:// doi.org/10.1158/0008-5472.CAN-10-1439. [PubMed]

52. Imtiyaz HZ, Williams EP, Hickey MM, Patel SA, Durham AC, Yuan LJ, Hammond R, Gimotty PA, Keith B, Simon MC. Hypoxia-inducible factor 2alpha regulates macrophage function in mouse models of acute and tumor inflammation. J Clin Invest. 2010; 120:2699-714. https://doi.org/10.1172/ JCI39506. [PubMed]

53. Wilson GK, Tennant DA, McKeating JA. Hypoxia inducible factors in liver disease and hepatocellular carcinoma: current understanding and future directions. J Hepatol. 2014; 61:1397-406. https://doi.org/10.1016/j. jhep.2014.08.025. [PubMed]

54. Nath B, Szabo G. Hypoxia and hypoxia inducible factors: diverse roles in liver diseases. Hepatology. 2012; 55:62233. https://doi.org/10.1002/hep.25497. [PubMed] 